OPEN ACCESS

Edited by:

Francesca Trojsi,

Università degli Studi della Campania

Luigi Vanvitelli Caserta, Italy

Reviewed by:

Judith Machts,

Universitätsklinikum

Magdeburg, Germany

Monica Consonni,

Istituto Neurologico Carlo Besta

(IRCCS), Italy

*Correspondence:

Peter Bede

bedep@tcd.ie

Specialty section:

This article was submitted to

Neurodegeneration,

a section of the journal

Frontiers in Neurology

Received: 28 October 2018 Accepted: 22 February 2019

Published: 19 March 2019

Citation:

Chipika RH, Finegan E, Li Hi Shing S, Hardiman O and Bede P (2019)

Tracking a Fast-Moving Disease:

Longitudinal Markers, Monitoring, and

Clinical Trial Endpoints in ALS.

Front. Neurol. 10:229.

doi: 10.3389/fneur.2019.00229

\section{Tracking a Fast-Moving Disease: Longitudinal Markers, Monitoring, and Clinical Trial Endpoints in ALS}

\author{
Rangariroyashe Hannah Chipika, Eoin Finegan, Stacey Li Hi Shing, Orla Hardiman and \\ Peter Bede*
}

Computational Neuroimaging Group, Biomedical Sciences Institute, Trinity College Dublin, Dublin, Ireland

Amyotrophic lateral sclerosis (ALS) encompasses a heterogeneous group of phenotypes with different progression rates, varying degree of extra-motor involvement and divergent progression patterns. The natural history of ALS is increasingly evaluated by large, multi-time point longitudinal studies, many of which now incorporate presymptomatic and post-mortem assessments. These studies not only have the potential to characterize patterns of anatomical propagation, molecular mechanisms of disease spread, but also to identify pragmatic monitoring markers. Sensitive markers of progressive neurodegenerative change are indispensable for clinical trials and individualized patient care. Biofluid markers, neuroimaging indices, electrophysiological markers, rating scales, questionnaires, and other disease-specific instruments have divergent sensitivity profiles. The discussion of candidate monitoring markers in ALS has a dual academic and clinical relevance, and is particularly timely given the increasing number of pharmacological trials. The objective of this paper is to provide a comprehensive and critical review of longitudinal studies in ALS, focusing on the sensitivity profile of established and emerging monitoring markers.

Keywords: motor neuron disease, amyotrophic lateral sclerosis, biomarkers, magnetic resonance imaging, neuroimaging

\section{INTRODUCTION}

Amyotrophic lateral sclerosis (ALS) is a clinically, genetically, and pathologically heterogeneous neurodegenerative condition (1-3). Clinical heterogeneity in ALS is multidimensional owing to variations in upper motor neuron (UMN) and lower motor neuron (LMN) involvement, extra-motor symptoms, age of onset, survival, and progression-rates. Disease heterogeneity hinders biomarker development $(3,4)$ which in turn impedes the reliable assessment of candidate drugs in clinical trials (1). Current clinical trials recruit relatively heterogeneous cohorts of symptomatic patients, despite the notion that considerable pathological changes can already be detected at the time of diagnosis $(5,6)$. The considerable variability in progression rates in ALS is another confounding factor in clinical trial designs $(1,7-10)$. Imaging and electrophysiological markers have been repeatedly proposed as candidate monitoring markers $(11,12)$, but it is increasingly clear that a panel of several "wet" and "dry" biomarkers may be required to capture subtle changes over short periods of time $(13,14)$. The objective of this paper is the comprehensive and critical review of longitudinal studies in ALS, focusing on study designs, statistical power, clinical correlations, the sensitivity profile of proposed monitoring markers and their applicability to clinical trials. 


\section{METHODS}

A formal literature search was performed on PubMed using the core search terms "amyotrophic lateral sclerosis" and "longitudinal" combined with each of the following keywords

\begin{abstract}
Abbreviations: 2D-DIGE, two-dimensional fluorescence difference gel electrophoresis; ABG, arterial blood gas; ACE-3, Addenbrookes Cognitive Examination - Third Edition; ACE-R, Addenbrooke's Cognitive Examinationrevised; $\mathrm{AD}$, axial diffusivity; $\mathrm{ADM}$, abductor digiti minimi; $\mathrm{ADQ}$, abductor digiti quinti; AGA, arterial gas analyses; AHB, abductor halluces brevis; ALS, amyotrophic lateral sclerosis; ALSAQ-40, ALS assessment questionnaire; ALSCBS, ALS Cognitive Behavior Screen; ALS-CFB, ALS computerized frontal battery; ALS-FBI, ALS-Frontal Behavioral Inventory; ALSFRS-r, revised ALS functional rating scale; ALSS, ALS severity scale; ALSSQoL-R, revised ALSspecific Quality of Life questionnaire; APB, abductor pollicis brevis; ARSLA, Association pour la recherche sur la SLA; ATLIS, accurate test of limb isometric strength; BAI, body adiposity index; BMI, body mass index; CALR, Calreticulin; CALSNIC, Canadian ALS Neuroimaging Consortium; CHI3L1, chitinase-3-like protein 1; CHI3L2, chitinase-3-like protein 2; CHIT1, chitotriosidase-1; Cho, Choline; CIDP, chronic inflammatory demyelinating polyneuropathy; CIS20-R, checklist individual strength; CK, creatinine kinase; CLIC1, Chloride intracellular channel protein 1; CMAP, compound muscle action potential; CMCT, central motor conduction time; CMT, Charcot-Marie-Tooth disease; CNS-BFS, Center for Neurologic Study-Bulbar Function Scale; CNS-LS, Center for Neurologic Study-Lability Scale; COWAT, controlled oral word association test; $\mathrm{Cr}$, creatinine; CSF, cerebrospinal fluid; CSP, cortical silence period; CypA, peptidyl-prolyl cistrans isomerase A; DCMAP, distal compound muscle action potential; D-KEFS, Delis-Kaplan Executive Function System; DTI, diffusion tensor imaging; DWI, diffusion-weighted imaging; ECAS, Edinburgh Cognitive and Behavioral ALS Screen; ECL, electrochemiluminescence; EDB, extensor digitorum brevis; EMG,
\end{abstract} electromyography; ERp57, protein disulfide-isomerase A3; EURALS, European Registry of ALS Consortium; EUROMOTOR, European multidisciplinary ALS network identification to cure motor neurone degeneration; FA, fractional anisotropy; $\mathrm{FAB}$, frontal assessment battery; $\mathrm{FBI}$, frontal behavioral inventory; FD, fiber density; FEV1, forced expiratory volume; fibs-sw, fibrillation/sharpwaves; FM-ADP, fat mass air displacement plethysmography; FPs, fasciculation potentials; FSS, fatigue severity scale; FUBP1, far upstream element-binding protein 1; FVC, forced vital capacity; GM, gray matter; GSTO1, glutathione S-transferase omega-1; HADS, hospital anxiety and depression scale; HDAC4, histone deacetylase 4; HHD, handheld dynamometry; HSC70, heat shock cognate $71 \mathrm{kDa}$ protein; IL, interleukin; IFN, interferon; IRAK4, Interleukin-1 receptorassociated kinase 4; JPND, EU Joint Programme for Neurodegenerative Disease Research; LGVF, letter guided verbal fluency; LMN, lower motor neuron; MAS, modified Ashworth scale; McDESPOT, multi-component driven equilibrium single pulse observation of T1/T2; MDRS-2, Mattis Dementia Rating scale-Second Edition; MEP, maximal static expiratory mouth pressure; MiND-B, motor neuron disease behavior scale; MIP, maximal inspiratory pressure; MiRNAs, micro-RNAs; MITOS, Milano-Torino staging system; MMSE, mini mental state examination; MMT, manual muscle testing; MND, Motor neuron disease; MoCA, Montreal Cognitive Assessment; MR, magnetic resonance; MRC, Medical Research Council Scale for muscle strength; MRCSS-LL, Medical Research Council sum score; MRI, magnetic resonance imaging; MRS, magnetic resonance spectroscopy; MS, multiple sclerosis; MU, motor unit; MUNE, motor unit number estimation; MUNIX, motor unit number index; MUPs, motor unit potentials; MUSIX, motor unit size index; NAA, N-acetylaspartate; NEALS, Northeast ALS Consortium; NFL, neurofilament light chain; NI, neurophysiology index; NISALS, Neuroimaging Society in Amyotrophic Lateral Sclerosis; NMR, nuclear magnetic resonance; nUHPLC LC-MS, nano ultra-high performance liquid chromatography tandem mass spectrometry; p75ECD, neurotrophin receptor p75 extracellular domain; PA28a, proteasome activator complex subunit 1; PBA, pseudobulbar affect; PCR, polymerase chain reaction; PDI, protein disulfide-isomerase; PEFT, peak expiratory flow time; PET, positron emission tomography; PGGM, precentral gyruses gray matter; PGRN, progranulin; PLS, primary lateral sclerosis; PMA, progressive muscular atrophy; pNFH, Phosphorylated neurofilament heavy chain; PRDX2, peroxiredoxin-2; PRO-ACT, Pooled Resource Open-Access ALS Clinical Trials; QoL, quality of life; RD, radial diffusivity; RMN, Research Motor separately: "staging," "monitoring," “outcomes," "clinical," "clinical trials," "electrophysiology," "neurophysiology," "electromyography," "transcranial magnetic stimulation," "motor unit number estimation," "motor unit number index," "positon emission tomography," "single photon emission computed tomography," "magnetic resonance imaging," "neuroimaging," "imaging," "blood," "urine," "cerebrospinal fluid," "saliva," and "muscle." A supplementary search combined the core search terms with the following keywords: "presymptomatic," "asymptomatic," and "post-mortem." Inclusion criteria included longitudinal studies investigating imaging, neurophysiological, clinical, or biofluid biomarkers in ALS. Animal studies, review papers, opinion pieces, editorials, case reports, and case series were excluded. Only articles written in English and published between January 1980 and August 2018 were reviewed. Based on the above criteria a total of 118 original research papers were selected and reviewed in accordance with the Preferred Reporting Items for Systematic Reviews and Meta-Analyses (PRISMA) recommendations.

\section{RESULTS}

\section{Neuroimaging}

The sample size characteristics, study design features, followup intervals of longitudinal neuroimaging, neurophysiology, and clinical studies are summarized in Table 1. Whilst most longitudinal imaging studies in ALS evaluate cerebral alterations (10), a number of promising spinal studies have now also been published. Spinal imaging has gradually overcome the technical challenges of physiological motion, small crosssectional dimensions and susceptibility gradients $(19,110-118)$. The majority of longitudinal studies in ALS are single-center studies eliminating the need for cross-platform MR sequence harmonization and inter-rater reliability tests. Given the low incidence of certain phenotypes such as primary lateral sclerosis (PLS), progressive muscular atrophy (PMA), and spinal and bulbar muscular atrophy (SBMA) however, multisite collaboration is often necessary (119). The infrastructure, funding and governance of such multicenter collaborations are now established via international consortia like the Neuroimaging Society in Amyotrophic Lateral Sclerosis (NISALS) or the Northeast ALS Consortium (NEALS) $(16,23,120,121)$. The need to include disease-controls in addition to healthy controls to describe ALS-specific changes

Neuron; ROA2, Heterogeneous nuclear ribonucleoproteins A2/B1; RSA, relative surface area; rsfMRI, resting state functional magnetic resonance imaging; SCA, spinocerebellar ataxia; SBMA, spinal and bulbar muscular atrophy; SEIQOL-DW, Schedule for the Evaluation of the Individual Quality of Life-Direct Weighting; SF-36, 36-Item short form health survey; SMA, spinal muscular atrophy; SMUAP, single motor unit action potential; SNIP, sniff nasal inspiratory pressure; SOD1, superoxide dismutase 1; SOP, Standard operating procedure; SPECT, single photon emission computed tomography; SPO2, peripheral capillary oxygen saturation; SVC, slow vital capacity; TA, tibialis anterior; TDP-43, TAR DNAbinding protein 43; TiM, Telehealth in Motor Neuron disease; TMS, transcranial magnetic stimulation; TNF, tumor necrosis factor; TUG, timed up and go test; Tw Pdi, twitch trans-diaphragmatic pressure; TWBC, total white blood cell count; UMN, upper motor neuron; VC, vital capacity; WALS, Western ALS Consortium; WVFI, Written Verbal Fluency Index. 
TABLE 1 | Longitudinal "dry biomarker" studies in ALS: Neuroimaging, Neurophysiology and Clinical Studies.

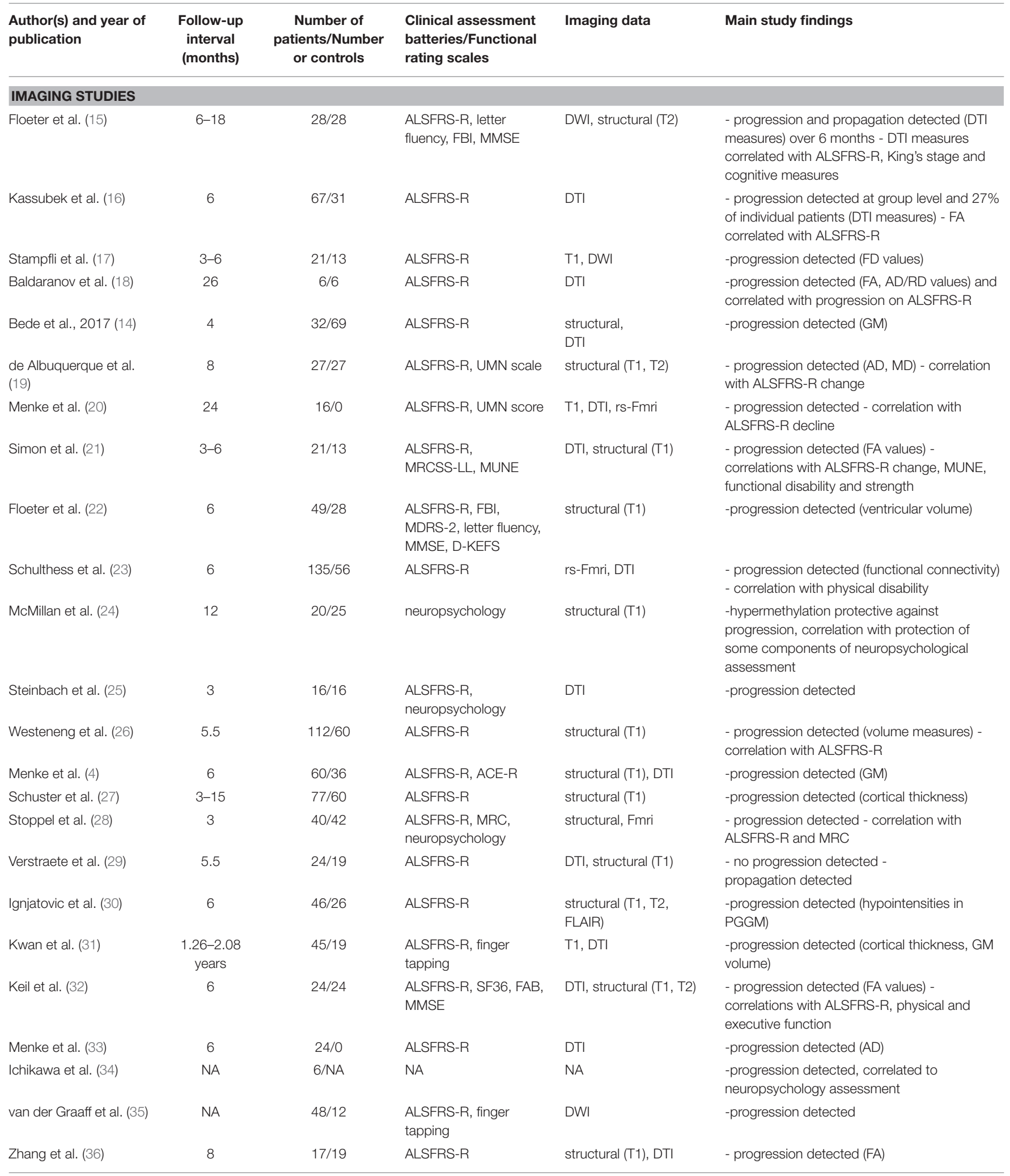


TABLE 1 | Continued

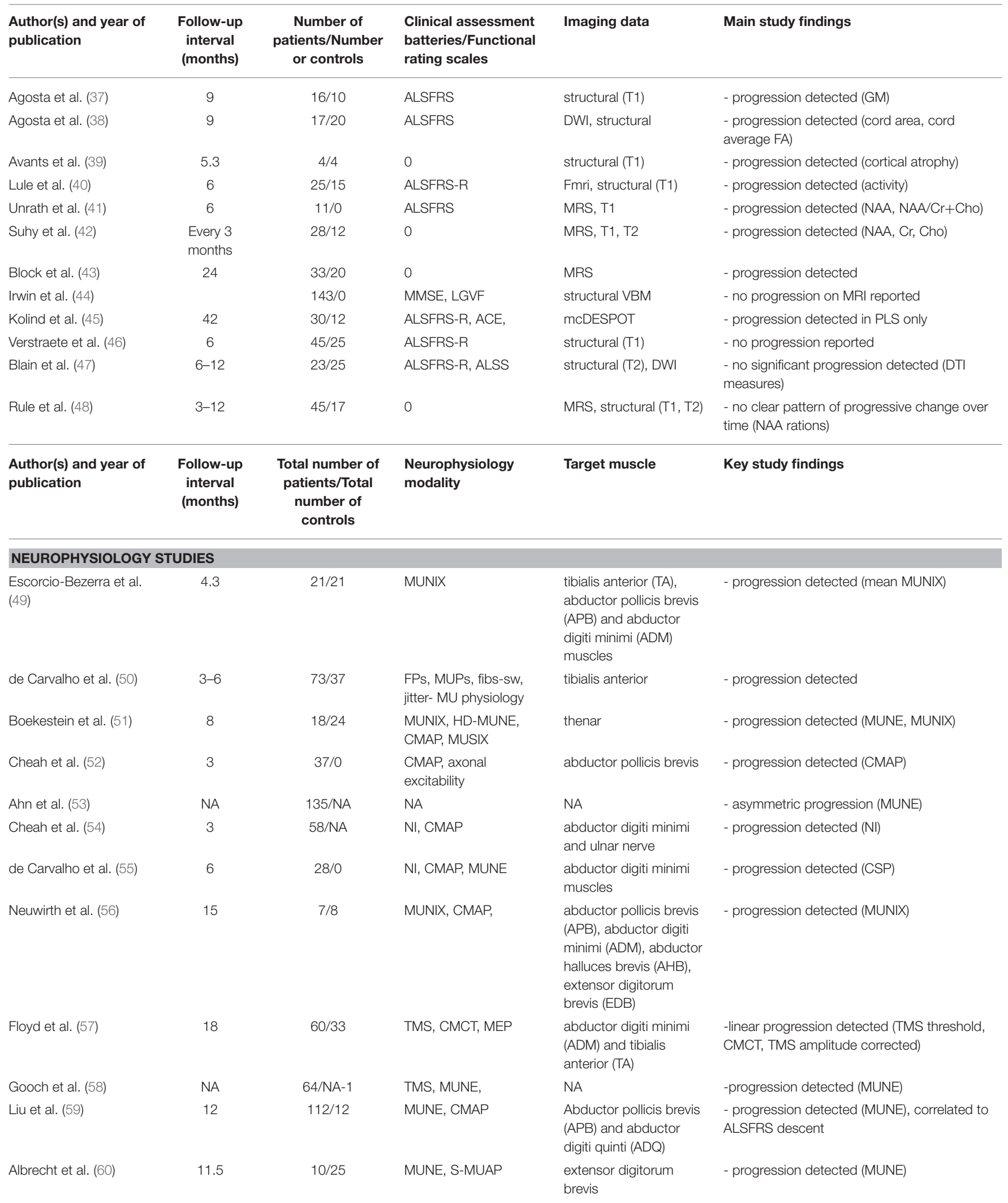


TABLE 1 | Continued

\begin{tabular}{|c|c|c|c|c|c|}
\hline $\begin{array}{l}\text { Author(s) and year of } \\
\text { publication }\end{array}$ & $\begin{array}{l}\text { Follow-up } \\
\text { interval } \\
\text { (months) }\end{array}$ & $\begin{array}{l}\text { Total number of } \\
\text { patients/Total } \\
\text { number of } \\
\text { controls }\end{array}$ & $\begin{array}{l}\text { Neurophysiology } \\
\text { modality }\end{array}$ & Target muscle & Key study findings \\
\hline Wang et al. (61) & 12 & $20 / 70$ & $\begin{array}{l}\text { MUNE, SMUP, CMAP, } \\
\text { MU loss }\end{array}$ & thenar & $\begin{array}{l}\text { - progression detected - (Thenar } \\
\text { MUNE, CMAP) }\end{array}$ \\
\hline Chan et al. (62) & 24 & NA & motor units & thenar & - progression detected \\
\hline Vucic et al. (65) & $7-100$ days & 25/30, 35 & $\begin{array}{l}\text { cortical and axonal } \\
\text { excitability- MEP, } \\
\text { CMAP- TMS }\end{array}$ & abductor pollicus brevis & - aim to determine effect of riluzole \\
\hline Aggarwal et al. (66) & 36 & $31 / 57$ & MUNE & $\begin{array}{l}\text { tibialis anterior, } \\
\text { abductor pollicis brevis } \\
\text { (APB), deltoid, and first } \\
\text { dorsal interosseous } \\
\text { muscles }\end{array}$ & - no progression reported \\
\hline de Carvalho et al. (68) & 11.6 & NA & CMAP, MEP, TMS & NA & - no progression detected \\
\hline Swash et al. (69) & NA & $14 / \mathrm{NA}$ & single fiber EMG & NA & - no definite progression detected \\
\hline
\end{tabular}

\begin{tabular}{lllll}
\hline Author(s) and year publication & $\begin{array}{l}\text { Follow-up } \\
\text { interval } \\
\text { (months) }\end{array}$ & $\begin{array}{l}\text { Number of } \\
\text { patients/Number of } \\
\text { controls }\end{array}$ & $\begin{array}{l}\text { Clinical assessment } \\
\text { batteries/Functional rating scales }\end{array}$ & Summary of findings
\end{tabular}

\section{CLINICAL STUDIES}

\section{ALSFRS-R}

Thakore et al. (70)

NA $\quad 3367 / 0$

Rooney et al. (71)

${ }^{*}$ ACTS trial. (72)

NA $\quad 407 / 0$

NA $\quad 75 /$ NA

75/NA

NA

Floeter et al. (73)

18

Elamin et al. (74)

NA

Roberts-South et al. (75)

24

186/NA

$16 / 12$

*Duning et al. (76)

3

10/32

Poletti et al. (77)

24

$168 / 0$

Xu et al. (78)

6

$108 / 60$

Gillingham et al. (79)

9

20/36

Mioshi et al. (80)

6

$79 / 53$

Quality of life assessments

Jakobsson Larsson et al. (81)
24
ALSFRS-R, ALSFRS, bloodscreatinine, uric acid, CK, albumin, sodium bicarbonate, hematocrit, TWBC

ALSFRS-R

ALSFRS

ALSFRS-R, letter fluency, FBI

cognitive testing

neuropsychology, language, discourse sampling, perfusion computerized transaxial tomography, pulmonary, clinical

ALSFRS, clinical neuropsychological battery, imaging

ECAS

ACE-3, FAB, ECAS executive, MoCA, ALSFRS-R, ALS-FTD-Q, MiND-B

ALS-CFB, ALSFRS-R

MiND-B- apathy, disinhibition, stereotypical behavior, ACE-R, ALSFRS-R

SEIQOL-DW, ALSFRS-R, HADS
- ALSFRS-R progression detected, pre-slope and post-slope have effects on survival

- progression detected in ALSFRS-R subscores progression detected (ALSFRS-R), associated with motor and pulmonary function

- progression detected (ALSFRS-R, FBI, letter fluency)

- progression detected (cognitive function)

- progression detected (cognitive language deficits)

- progression detected (DTI)

- no progression detected, ECAS scores improved over time

- no progression detected

- no progression reported

- no progression reported

- anxiety decreased over time, depression correlated to QOL, QOL remained stable despite physical deterioration 
TABLE 1 | Continued

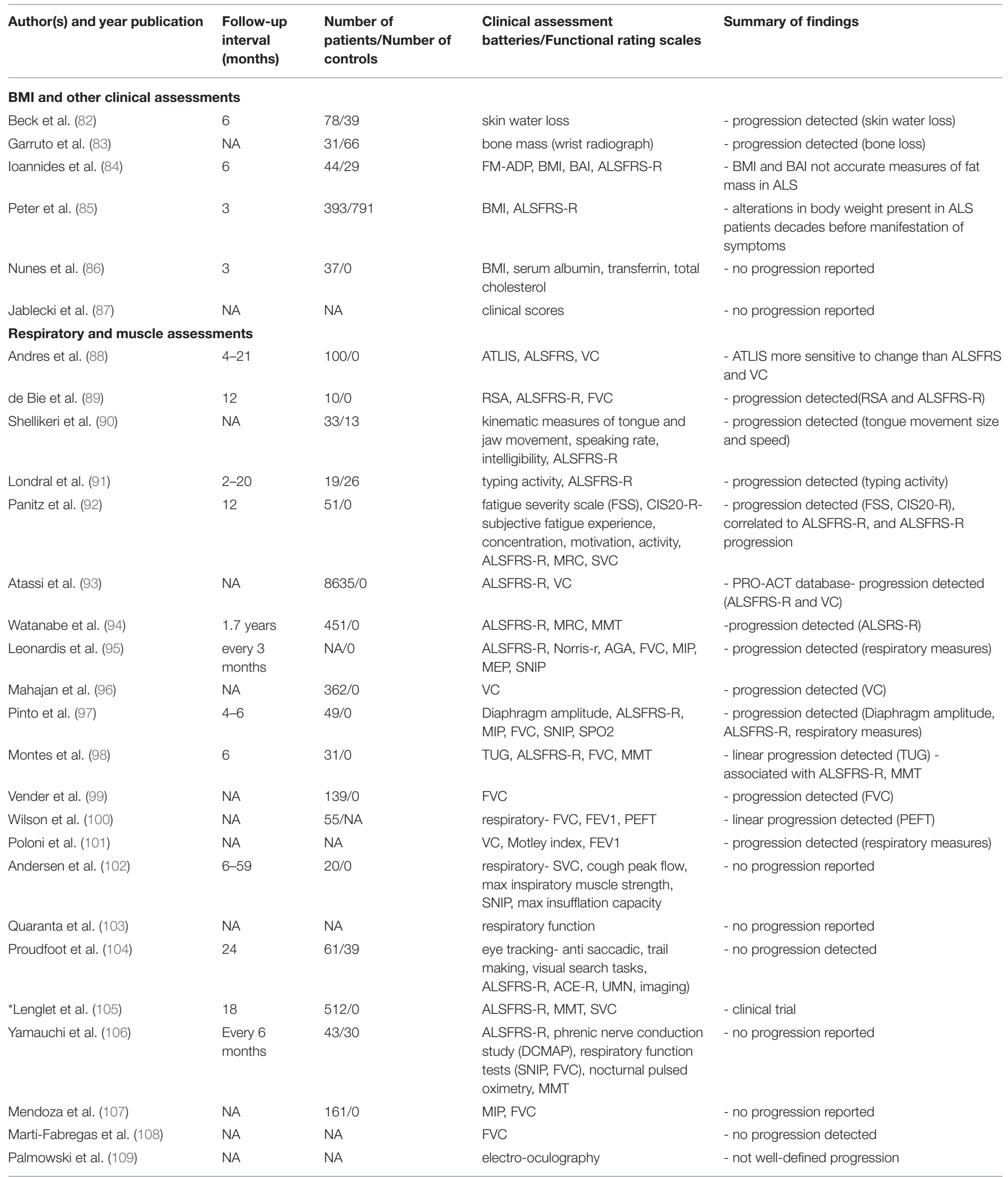

Studies detecting progressive changes are listed first followed by studies not capturing longitudinal changes. *indicates clinical trial. 
is increasingly recognized $(30,43,44)$. With few exceptions (122-124), most ALS imaging studies use 3 Tesla platforms and 7 Tesla systems are more commonly used in post-mortem studies $(125,126)$. Disease progression has been detected across a range of MR imaging metrics including structural $(22,26)$, diffusion $(16,18)$, functional $(28,40)$, and spectroscopy $(41,42)$ measures. As the majority of studies have a two-timepoint design, it is often unclear if specific imaging metrics show linear or exponential changes. The few existing multi-timepoint studies suggest that pathological change is not linear (10). The revised ALS functional rating scale (ALSFRS-r) is the most commonly reported clinical measure $(16,18-20)$, with only few imaging studies reporting associations with staging (15) or neuropsychological performance $(15,24)$.

\section{Neurophysiology}

Most longitudinal neurophysiology studies are single center studies, reducing the risk of inter-rater and inter-center variability (127). As presented in Table 1, follow-up interval ranges between 7 days (65) and 3 years (66), and up to 7 follow-up time-points have been included in some studies (57, 60). Surprisingly few studies include disease controls such as peripheral neuropathy (60) or benign fasciculation syndrome (50). Clinical assessments performed in conjunction with neurophysiology typically include ALSFRS-r (51), forced vital capacity (FVC) (55), slow vital capacity (SVC) (56), grip strength (64), pinch strength (58), and manual muscle testing (MMT) (58), however, correlations between neurophysiological measures and clinical assessments are seldom reported. The majority of longitudinal neurophysiological studies focus on upper limb muscles, e.g., abductor pollicis brevis, deltoid, first dorsal interrosseus, extensor digitorum brevis, abductor digiti minimi $(51,52,55,60,61)$ with relatively few studies evaluating lower limb muscles such as abductor hallicus brevis and tibialis anterior $(50,56,57,66)$. The most commonly reported longitudinal neurophysiological indices include compound muscle action potential (CMAP) $(51,52)$, single motor unit action potential (SMUAP) $(60), \operatorname{MUNE}(55,59), \operatorname{MUNIX}(49,56)$, neurophysiology index (NI) $(54,55)$, TMS measures $(57,58)$, and axonal excitability (52). Progressive neurophysiological changes have been detected by MUNIX (49, 51, 56), MUNE (51, 58, 60), CMAP (52, 61), NI (54), and TMS measures (57) and allowing for study-design limitations, the consensus is that degenerative changes are not linear.

\section{Clinical Biomarkers and Instruments}

Robust clinical longitudinal studies in ALS have up to 6 followup time points $(88,89,91)$, the interval between the assessments can be as short as 3 months (95) and the sample size can be as big as several thousands $(70,93)$ (Table 1). Few multi-timepoint studies include disease controls such as motor neuropathies (91), alternative neuromuscular diseases (78), or neurodegenerative conditions (83). Large, multi-timepoint longitudinal studies invariably suffer from considerable attrition rates, but these are rarely explicitly reported in the manuscript abstracts (10). Detailed genotyping is only available in a minority of longitudinal studies $(15,77,79,94)$. The most widely utilized rating scale in longitudinal studies is the ALSFRS-r (70, 71, 128) which provides a composite score of bulbar, limb and respiratory dysfunction, and is invariably evaluated in clinical trials (72, 105). Quality of life (QoL) in ALS is increasingly evaluated by disease-specific instruments such as the 40-item ALS assessment questionnaire (ALSAQ-40) or the revised ALS-specific Quality of Life questionnaire (ALSSQoL-R) (129-131). A number of symptom-specific instruments are also commonly used such as the Center for Neurologic Study-Bulbar Function Scale (CNSBFS), a 21-item self-report scale of bulbar function, and the Center for Neurologic Study-Lability Scale (CNS-LS), a 7-item self-report scale of pseudobulbar affect (PBA) (132). Tapping rates, composite reflex scores, The Penn UMN Score (133), the Modified Ashworth scale (MAS) are often used as proxies of UMN degeneration (132).

In clinical trials, muscle strength is often estimated by handheld dynamometry (HHD) (134), manual muscle testing (MMT) (105), scoring systems such as the Medical Research Council (MRC) Scale for muscle strength (135) and some studies also report limb circumference (136). Respiratory function in ALS is typically monitored by sniff nasal inspiratory pressure (SNIP), SVC, or FVC in addition to measures such as early morning arterial blood gas $(\mathrm{ABG})$ and overnight pulse-oximetry (137, 138). Measures of typing ability (91), tongue movements (90), vital capacity (VC) (96), FVC (99), SNIP (97), and diaphragm amplitude (97) all show progressive longitudinal changes. Nutritional markers such as body mass index (BMI) and lipid profile are now established prognostic indicators (139, 140). Cognitive and behavioral domains are routinely assessed thanks to the availability of validated screening instruments such as the Edinburgh Cognitive and Behavioral ALS Screen (ECAS) (141), the Beaumont Behavioral Inventory (BBI) (142) and the ALS Cognitive Behavioral Screen (ALS-CBS) (143). In contrast to the relentlessly progressive motor deficits of ALS, the trajectory of cognitive and behavioral deficits is less clear due to considerable individual variations, genotype-associated profiles $(144,145)$, differences in assessment strategies and practiceeffects (146). Several longitudinal neuropsychology studies do not detect progression $(77,147,148)$, progressive behavioral impairment has been noted in the absence of cognitive change (149), and some studies report improved performance as a result of practice effects (77).

\section{Wet Biomarkers}

The findings, study design characteristics, and follow-up intervals of longitudinal biofluid studies are summarized in Table 2. Phosphorylated neurofilament heavy chain ( $\mathrm{pNFH})$, neurofilament light chain (NF-L), progranulin (PGRN), cytokines, TAR DNA-binding protein 43 (TDP-43), cystatin C, creatinine, micro-RNAs (miRNAs), chitotriosidase-1 (CHIT1), chitinase-3-like protein 1 (CHI3L1), chitinase-3-like protein 2 (CHI3L2) have been evaluated in both research studies $(152,153,157,158,162,164,168,171)$ and clinical trials $(150,156,157,160,161)$. Markers of iron metabolism and ferroptosis are relatively recent domains of ALS biomarker research $(172,173)$. Most biofluid studies are either serum $(150,157)$ or CSF studies $(152,167)$, but urine (155) and skeletal 


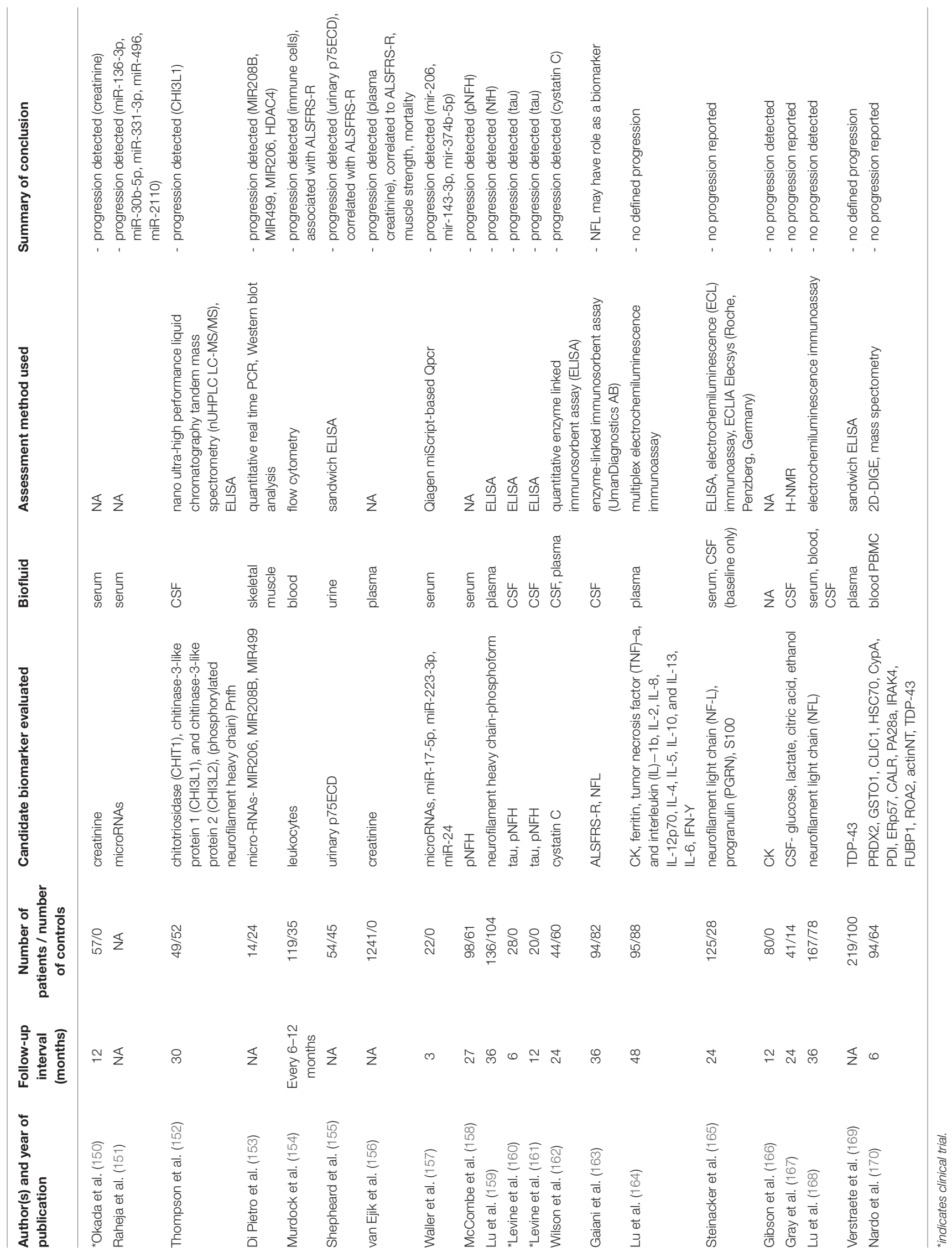


muscle-based (153) studies have now also been published. Quantitative enzyme-linked immunosorbent assay (ELISA) is the most commonly used antibody-based technique $(13,174)$ which can be performed with one antibody (indirect ELISA), or with two antibodies (sandwich ELISA). Increased CSF (13) and serum (175) pNFH detected by ELISA is thought to be a sensitive marker of axonal degeneration in ALS $(152,171,176,177)$. The specificity of this marker however may be inadequate to reliably differentiate ALS from other neurodegenerative conditions $(13,176)$. Other antibody-based techniques such as Western blot (171) and electrochemiluminescence (ECL) (153, 168) may improve detection sensitivity and reliability (13). Panels of multiple proteins can be evaluated by multiplex immunoassays such as planar or microbead assays (13). Mass spectrometry based methods using chromatin-immunoprecipitation-based surfaces, two-dimensional gel electrophoresis or high-resolution mass spectrometry have identified cystatin- $\mathrm{C}$ and transthyretin as candidate biomarkers (178-180). The longest wet biomarker study followed patients for 4 years (164). The majority of studies have at least 2 follow-up timepoints $(155,162,170)$ and one study included 13 follow-up timepoints $(156,159)$. Large multi-center trials include as much as 1,000 participants (156). One of the most striking shortcomings of existing longitudinal studies is that very few included disease controls such as Parkinson's disease cohorts, patients with multifocal motor neuropathy with conduction block, Kennedy's disease, chronic inflammatory demyelinating polyneuropathy (CIDP), cervical or lumbar radiculopathy, Charcot-Marie-Tooth disease (CMT), benign fasciculation, and cramp syndrome etc. (152, 159, 162). Another limitation of many longitudinal studies is the lack of comprehensive genotyping (12) as very few studies report comprehensive screening for ALS-associated mutations (153, 159, 169, 171). Exhaustive clinical profiling, such as medications (152, 164), neuropsychological assessments (171), quality of life indices are rarely reported in longitudinal studies. The majority of studies limit their clinical descriptions to ALSFRS-r, FVC, MRC, and Ashworth scores $(153,161,162)$. Serum and plasma biomarkers such as creatinine $(150,156)$, pNfH $(158,159)$, and micro-RNAs (157), CSF biomarkers such as CHI3L1 (152), tau (160, 161), and cystatin-C (162), and urinary (155) and skeletal muscle (153) biomarkers are some of the promising tools for detecting disease progression. While no progressive changes have been detected in NFL levels, it is likely to be a useful as a diagnostic biomarker $(168,171)$.

\section{Studies of Asymptomatic Mutation Carriers}

Current clinical trials only recruit symptomatic cases despite accruing evidence that ALS has a long presymptomatic phase (5). Imaging studies of asymptomatic mutation carriers have consistently confirmed disease-specific cerebral and spinal cord changes prior to symptom onset (181-184) indicating that this disease-phase may represent a crucial window for therapeutic or neuroprotective intervention. The majority of presymptomatic studies assess a single time-point, as opposed to the longitudinal tracking of asymptomatic carriers of ALS-causing mutations (15). While the overwhelming majority of presymptomatic studies focus on C9orf72 hexanucleotide carriers (183, 185187), no prognostic markers have been validated to predict whether single patients will develop ALS or FTD. Compared to imaging studies, strikingly few presymptomatic neurophysiology studies have been undertaken (66). Studies of asymptomatic ALScausing mutation carriers have enormous potential for academic research and may pave the way for asymptomatic pharmaceutical trials $(5,181)$.

\section{DISCUSSION}

Clinical trials currently evaluate the efficacy of candidate drugs using the revised ALS functional rating scale (ALSFRS-r), muscle strength assessment tools such as manual muscle testing (MMT), respiratory function indices such as forced vital capacity (FVC), slow vital capacity (SVC) and sniff nasal inspiratory pressure (SNIP), neurophysiological measures and survival (102, 116, $120,188,189)$. These measures however primarily reflect latestage functional impairment and are not indicative of early stage pathology. Brain and spinal cord imaging has been evaluated as early-stage biomarkers with both diagnostic and monitoring potential $(116,120,190)$. The core neuroimaging signature of ALS, irrespective of the disease-stage, includes corticospinal tract $(191,192)$, corpus callosum (193) and motor cortex degeneration (194). Atrophy in frontotemporal regions has been primarily associated with neuropsychological deficits (195-197) and linked to hexanucleotide repeats in C9orf72 $(145,198)$. Longitudinal imaging studies are superior to crosssectional studies as they readily detect dynamic structural and functional changes and may elucidate compensatory processes $(10,14,23,28,40,120,199)$. The emergence of multi-timepoint study designs $(14,20)$ enable the characterization of anatomical propagation patterns (200) and provide invaluable temporal insights into the disease trajectory of late-stage ALS. Interscan intervals as short as 3 months can detect longitudinal changes $(14,18,120)$. Many longitudinal studies make use of multiple magnetic resonance (MR) metrics which is particularly useful in establishing an optimal panel of monitoring markers (120). Several longitudinal studies have indicated that white matter degeneration can be detected relatively early in the course of ALS with restricted further progression over time, whereas gray matter pathology shows relentless progression in the symptomatic phase of the disease $(4,14,120)$. In addition to structural imaging studies, connectivity-based, metabolic, peripheral nerve, and, whole body muscle imaging have contributed to our understanding of longitudinal changes (20, 201-203).

Needle electromyography and nerve conduction studies play an important clinical role in ruling out alternative conditions and confirming a suspected diagnosis of ALS. Despite variations in local protocols, neurophysiological tests are recognized as objective, reliable and cost-effective tests of neuromuscular dysfunction, and have also been repeatedly proposed as longitudinal markers $(55,204)$. CMAP is generated by depolarization of muscle fibers through the stimulation of a single nerve, where amplitude reductions are interpreted as 
loss of motor axons $(205,206)$. While CMAP measurements capture longitudinal decline, it is confounded by variations in temperature, limb positioning and electrode placement $(56,207)$. CMAP-derived measures such as MUNE and MUNIX are now extensively utilized to characterize progressive changes in ALS. MUNE estimates motor neuron numbers, and may detect the rate of motor neuron loss, making it a more reliable method of appraising disease progression than $\operatorname{CMAP}(208,209)$. However, its early-phase sensitivity has been questioned, as its use is limited to distal muscles, and the technique requires considerable training, especially for inter-rater and multi-site comparisons $(205,210)$. TMS allows the characterization of upper motor neuron dysfunction, and may be particularly useful in detecting progressive changes $(57,205)$.

Functional rating-scales are often the monitoring instruments of choice in clinical trials (55), as they are easy to administer, cost-effective to utilize and have acceptable inter- and intrarater reliability profiles (7). The most widely used rating scale in clinical longitudinal studies is the ALSFRS-r. Despite its ease of administration, it has considerable limitations, as it may be disproportionately influenced by LMN dysfunction, does not account for laterality or asymmetry of symptoms, omits cognitive impairment, and may be affected by medications $(14,128,188,211)$.

Proteomics, metabolomics and lipidomics have seen significant advances in ALS research and CSF and serum markers are now used in longitudinal academic and pharmacological studies (172). Potential biomarkers for the detection of disease progression include serum and plasma biomarkers such as creatinine $(150,156)$, pNfH $(158,159)$, and micro-RNAs (157), CSF biomarkers such as CHI3L1 (152), tau (160, 161), and cystatin-C (162), and urinary (155) and skeletal muscle (153) biomarkers.

\section{Prediction Analyses}

Age at symptom onset (212), BMI (139), bulbar involvement (213), cognitive impairment (214), C9orf72 genotype status (144), respiratory insufficiency (215), “definite ALS" by the El Escorial criteria (216), and functional disability (217) are the most commonly cited determinants of poor prognosis in ALS. SNIP (218) and less commonly used measures such as twitch trans-diaphragmatic pressure (Tw Pdi) (219) and maximal static expiratory mouth pressure (MEP) were shown to be good predictors of ventilator-free survival (219). A combined panel of several clinical, wet, and dry biomarkers is likely to offer the most accurate prognostic information $(115,120,216,217,220)$. While cerebral $(217,221,222)$ and spinal (115) imaging measures have been repeatedly linked to survival outcomes, these have not been utilized in a clinical setting. Neurophysiological variables, such as phrenic nerve stimulation outcomes (223) and biofluid markers, such as pNFH and NFL $(165,168,224-226)$ are also thought to be accurate predictors.

\section{Patient Stratification}

Attempts to enroll patients in the early stages of the disease are hampered by the universally long diagnostic delay in ALS (227). Patient stratification in trials is typically based on site of onset (228), instead of other variables which have an established prognostic impact $(138,229)$. Admixed patient cohorts within a trial may hamper the ability to detect how different phenotypes and genotypes may exhibit a different response to a candidate drug (230-232). The stratification of heterogeneous cohorts is now aided by the development of validated staging systems, such as the King's (233), Milano-Torino (MITOS) (234) or the Fine'til 9 (FT9) (235) staging systems. The King's Staging system is based on the number of body regions affected, and the presence of nutritional or respiratory failure (233). The MITOS staging system is based on the ALSFRS-r, and is particularly sensitive to changes in later stages of the disease $(236,237)$. However, none of these staging systems account for cognitive or behavioral changes (236). Pathological staging systems suggest a four-stage model of ALS based on anatomical patterns of pTDP-43 load $(238,239)$. This system has now been validated by in vivo neuroimaging studies (240) and signals that accurate pathological staging and patient stratification may be possible based on neuroimaging $(199,240)$.

\section{International Consortia}

Only few ALS centers maintain dedicated biobanking facilities to store and process molecular markers in human biofluid locally. Similarly, relatively few centers are in a position to generate sufficient number of MRI and neurophysiology data sets of rare phenotypes to make meaningful inferences in a single center setting. Brain and tissue banks are also challenging to establish, maintain and fund, despite their invaluable contribution to ALS research (241-243).

Biospecimen samples are also often collected during clinical trials, and discarded after negative outcomes, despite their enormous potential for biomarker discovery (172). One of the most important achievements of biomarker development efforts is the establishment of national and international research consortia such as Association pour la recherche sur la SLA (ARSLA), Neuroimaging Society in ALS (NISALS), Research Motor Neuron (RMN), Canadian ALS Neuroimaging Consortium (CALSNIC), EU Joint Programme for Neurodegenerative Disease Research (JPND), European multidisciplinary ALS network identification to cure motor neurone degeneration (EUROMOTOR) which maintain vital biobanking facilities, registries, data repositories for multicenter data interpretation $(121,244)$. Clinical trial networks are also increasingly recognized as valuable platforms for multisite data collection and interpretation as they operate with carefully standardized protocols. Consortia such as the European Registry of ALS (EURALS) Consortium, the Western ALS (WALS) Consortium and the Northeast ALS (NEALS) Consortium are other examples (245). NEALS is one of the largest consortia with over 100 member sites from the US, Canada, Mexico, Italy, Lebanon and Australia (246). EURALS coordinates research studies and clinical trials relying on population-based European registries and include centers from Scotland, England, Netherlands, Spain, Ireland, Serbia, Italy, France, and Germany $(241,247,248)$. ALS research consortia promote patient-oriented research, maintain biofluid, imaging and DNA banks, and have 
the potential to translate scientific advances into pragmatic clinical interventions.

\section{Telehealth}

Novel trends in longitudinal data collection include telemedicine-based technologies, wearable sensors and mobile phone applications (230). The continuous collection of data via telephone or telemedicine applications such as the Telehealth in Motor Neuron disease (TiM) system circumvent the inconvenience of patients and caregivers traveling long distances for research appointments (249). Once local data-protection and governance guidelines are complied with, information uploaded from these systems can be made available to healthcare professionals of multidisciplinary teams in real time (249). The feasibility of telehealth for ALS patients via live videoconferencing has also been evaluated (250) and is considered a particularly promising clinical and research platform $(249,250)$. A number of cognitive-behavioral screening tools have also been adapted for phone administration (251) including modified versions of the ALS Cognitive Behavior Screen (ALS-CBS), the Controlled Oral Word Association Test (COWAT), the Center for Neurologic Study-Lability Scale (CNS-LS) and found to be statistically equivalent to face-to-face assessments (251). Performance on other tests however, such as the telephone versions of the ALS-Frontal Behavioral Inventory (ALS-FBI) caregiver interview and the Written Verbal Fluency Index (WVFI) was not equivalent to clinic-based assessments (251). The continued development of telephone and internet-enabled

\section{REFERENCES}

1. Katyal N, Govindarajan R. Shortcomings in the current amyotrophic lateral sclerosis trials and potential solutions for improvement. Front Neurol. (2017) 8:521. doi: 10.3389/fneur.2017.00521

2. Miller. Riluzole for amyotrophic lateral sclerosis (ALS)/motor neuron disease (MND). Cochrane Database Syst Rev. (2002) 14:CD001447. doi: 10.1002/14651858.CD001447

3. Al-Chalabi A, Jones A, Troakes C, King A, Al-Sarraj S, van den Berg LH. The genetics and neuropathology of amyotrophic lateral sclerosis. Acta Neuropathol. (2012) 124:339-52. doi: 10.1007/s00401-012-1022-4

4. Menke RA, Korner S, Filippini N, Douaud G, Knight S, Talbot K, et al. Widespread grey matter pathology dominates the longitudinal cerebral MRI and clinical landscape of amyotrophic lateral sclerosis. Brain. (2014) $137(\mathrm{Pt}$ 9):2546-55. doi: 10.1093/brain/awu162

5. Eisen A, Kiernan M, Mitsumoto H, Swash M. Amyotrophic lateral sclerosis: a long preclinical period? J Neurol Neurosurg Psychiatry. (2014) 85:1232-8. doi: 10.1136/jnnp-2013-307135

6. Benatar M, Wuu J. Presymptomatic studies in ALS: rationale, challenges, and approach. Neurology. (2012) 79:1732-9. doi: 10.1212/WNL.0b013e31826e9b1d

7. Mitsumoto H, Brooks BR, Silani V. Clinical trials in amyotrophic lateral sclerosis: why so many negative trials and how can trials be improved? Lancet Neurol. (2014) 13:1127-38. doi: 10.1016/S1474-4422(14)70129-2

8. Beghi E, Chio A, Couratier P, Esteban J, Hardiman O, Logroscino G, et al. The epidemiology and treatment of ALS: focus on the heterogeneity of the disease and critical appraisal of therapeutic trials. Amyotroph Lateral Scler. (2011) 12:1-10. doi: 10.3109/17482968.2010.502940

9. de Carvalho M, Swash M. Can selection of rapidly progressing patients shorten clinical trials in amyotrophic lateral sclerosis? Arch Neurol. (2006) 63:557-60. doi: 10.1001/archneur.63.4.557 devices are likely to provide further insights to longitudinal physical, cognitive and behavioral changes (251).

\section{CONCLUSIONS}

While clinical indicators of disease progression remain indispensable, neuroimaging, neurophysiology, and biofluid measures are particularly promising, objective, quantitative biomarker candidates. The validation of combined "wet" and "dry" biomarker panels will not only enable the detection of subtle progressive changes in ALS, but allow precision stratification of heterogeneous patient cohorts in clinical trials and improve existing prediction algorithms.

\section{AUTHOR CONTRIBUTIONS}

The manuscript was drafted by RC. EF, SL, OH and $\mathrm{PB}$ contributed to the conceptualization, editing, and revision of this paper.

\section{FUNDING}

This work was supported by the Andrew Lydon Scholarship, the Health Research Board (HRB-Ireland; HRB EIA-2017-019), the Irish Institute of Clinical Neuroscience (IICN)-Novartis Ireland Research Grant, the Iris O'Brien Foundation, the Perrigo Clinician-Scientist Research Fellowship, and the Research Motor Neuron (RMN-Ireland) Foundation.

10. Schuster C, Elamin M, Hardiman O, Bede P. Presymptomatic and longitudinal neuroimaging in neurodegeneration-from snapshots to motion picture: a systematic review. J Neurol Neurosurg Psychiatry. (2015) 86:108996. doi: 10.1136/jnnp-2014-309888

11. Turner MR, Agosta F, Bede P, Govind V, Lule D, Verstraete E. Neuroimaging in amyotrophic lateral sclerosis. Biomark Med. (2012) 6:31937. doi: $10.2217 / \mathrm{bmm} .12 .26$

12. Bede P, Hardiman O. Lessons of ALS imaging: pitfalls and future directions - a critical review. NeuroImage Clin. (2014) 4:436-43. doi: 10.1016/j.nicl.2014.02.011

13. Bowser R, Turner MR, Shefner J. Biomarkers in amyotrophic lateral sclerosis: opportunities and limitations. Nat Rev Neurol. (2011) 7:631-8. doi: 10.1038/nrneurol.2011.151

14. Bede P, Hardiman O. Longitudinal structural changes in ALS: a three time-point imaging study of white and gray matter degeneration. Amyotroph Lateral Scler Frontotemporal Degener. (2018) 19:232-41. doi: 10.1080/21678421.2017.1407795

15. Floeter MK, Danielian LE, Braun LE, Wu T. Longitudinal diffusion imaging across the C9orf72 clinical spectrum. J Neurol Neurosurg Psychiatry. (2018) 89:53-60. doi: 10.1136/jnnp-2017-316799

16. Kassubek J, Muller HP, Del Tredici K, Lule D, Gorges M, Braak H, et al. Imaging the pathoanatomy of amyotrophic lateral sclerosis in vivo: targeting a propagation-based biological marker. J Neurol Neurosurg Psychiatry. (2018) 89:374-81. doi: 10.1136/jnnp-2017-316365

17. Stampfli P, Sommer S, Czell D, Kozerke S, Neuwirth C, Weber M, et al. Investigation of neurodegenerative processes in amyotrophic lateral sclerosis using white matter fiber density. Clin Neuroradiol. (2018). doi: 10.1007/s00062-018-0670-8. [Epub ahead of print].

18. Baldaranov D, Khomenko A, Kobor I, Bogdahn U, Gorges M, Kassubek J, et al. Longitudinal diffusion tensor imaging-based assessment of tract alterations: an application to amyotrophic lateral 
sclerosis. Front Hum Neurosci. (2017) 11:567. doi: 10.3389/fnhum. 2017.00567

19. de Albuquerque M, Branco LM, Rezende TJ, de Andrade HM, Nucci A, Franca MC Jr. Longitudinal evaluation of cerebral and spinal cord damage in Amyotrophic Lateral Sclerosis. NeuroImage Clin. (2017) 14:269-76. doi: 10.1016/j.nicl.2017.01.024

20. Menke RAL, Proudfoot M, Talbot K, Turner MR. The two-year progression of structural and functional cerebral MRI in amyotrophic lateral sclerosis. Neuroimage Clin. (2018) 17:953-61. doi: 10.1016/j.nicl.2017.12.025

21. Simon NG, Lagopoulos J, Paling S, Pfluger C, Park SB, Howells $\mathrm{J}$, et al. Peripheral nerve diffusion tensor imaging as a measure of disease progression in ALS. J Neurol. (2017) 264:882-90. doi: $10.1007 / \mathrm{s} 00415-017-8443-\mathrm{x}$

22. Floeter MK, Bageac D, Danielian LE, Braun LE, Traynor BJ, Kwan JY. Longitudinal imaging in C9orf72 mutation carriers: relationship to phenotype. NeuroImage Clin. (2016) 12:1035-43. doi: 10.1016/j.nicl.2016.10.014

23. Schulthess I, Gorges M, Muller HP, Lule D, Del Tredici K, Ludolph AC, et al. Functional connectivity changes resemble patterns of pTDP-43 pathology in amyotrophic lateral sclerosis. Sci Rep. (2016) 6:38391. doi: 10.1038/srep38391

24. McMillan CT, Russ J, Wood EM, Irwin DJ, Grossman M, McCluskey L, et al. C9orf72 promoter hypermethylation is neuroprotective: neuroimaging and neuropathologic evidence. Neurology. (2015) 84:1622-30. doi: 10.1212/WNL.0000000000001495

25. Steinbach R, Loewe K, Kaufmann J, Machts J, Kollewe K, Petri S, et al. Structural hallmarks of amyotrophic lateral sclerosis progression revealed by probabilistic fiber tractography. J Neurol. (2015) 262:2257-70. doi: 10.1007/s00415-015-7841-1

26. Westeneng H-J, Verstraete E, Walhout R, Schmidt R, Hendrikse J, Veldink $\mathrm{JH}$, et al. Subcortical structures in amyotrophic lateral sclerosis. Neurobiol Aging. (2015) 36:1075-82. doi: 10.1016/j.neurobiolaging.2014.09.002

27. Schuster C, Kasper E, Machts J, Bittner D, Kaufmann J, Benecke R, et al. Longitudinal course of cortical thickness decline in amyotrophic lateral sclerosis. J Neurol. (2014) 261:1871-80. doi: 10.1007/s00415-014-7426-4

28. Stoppel CM, Vielhaber S, Eckart C, Machts J, Kaufmann J, Heinze HJ, et al. Structural and functional hallmarks of amyotrophic lateral sclerosis progression in motor- and memory-related brain regions. NeuroImage Clin. (2014) 5:277-90. doi: 10.1016/j.nicl.2014.07.007

29. Verstraete E, Veldink JH, van den Berg LH, van den Heuvel MP. Structural brain network imaging shows expanding disconnection of the motor system in amyotrophic lateral sclerosis. Hum Brain Mapp. (2014) 35:1351-61. doi: $10.1002 / \mathrm{hbm} .22258$

30. Ignjatovic A, Stevic Z, Lavrnic S, Dakovic M, Bacic G. Brain iron MRI: a biomarker for amyotrophic lateral sclerosis. J Magn Reson Imaging. (2013) 38:1472-9. doi: 10.1002/jmri.24121

31. Kwan JY, Meoded A, Danielian LE, Wu T, Floeter MK. Structural imaging differences and longitudinal changes in primary lateral sclerosis and amyotrophic lateral sclerosis. Neuroimage Clin. (2012) 2:151-60. doi: 10.1016/j.nicl.2012.12.003

32. Keil C, Prell T, Peschel T, Hartung V, Dengler R, Grosskreutz J. Longitudinal diffusion tensor imaging in amyotrophic lateral sclerosis. BMC Neurosci. (2012) 13:141. doi: 10.1186/1471-2202-13-141

33. Menke RA, Abraham I, Thiel CS, Filippini N, Knight S, Talbot K, et al. Fractional anisotropy in the posterior limb of the internal capsule and prognosis in amyotrophic lateral sclerosis. Arch Neurol. (2012) 69:1493-9. doi: 10.1001/archneurol.2012.1122

34. Ichikawa $\mathrm{H}$, Ohno H, Murakami H, Ohnaka Y, Kawamura M. Writing error may be a predictive sign for impending brain atrophy progression in amyotrophic lateral sclerosis: a preliminary study using X-ray computed tomography. Eur Neurol. (2011) 65:346-51. doi: 10.1159/000328216

35. van der Graaff MM, Sage CA, Caan MW, Akkerman EM, Lavini C, Majoie $\mathrm{CB}$, et al. Upper and extra-motoneuron involvement in early motoneuron disease: a diffusion tensor imaging study. Brain. (2011) 134(Pt 4):1211-28. doi: 10.1093/brain/awr016

36. Zhang Y, Schuff N, Woolley SC, Chiang GC, Boreta L, Laxamana J, et al. Progression of white matter degeneration in amyotrophic lateral sclerosis: a diffusion tensor imaging study. Amyotroph Lateral Scler. (2011) 12:421-9. doi: $10.3109 / 17482968.2011 .593036$
37. Agosta F, Gorno-Tempini ML, Pagani E, Sala S, Caputo D, Perini M, et al. Longitudinal assessment of grey matter contraction in amyotrophic lateral sclerosis: a tensor based morphometry study. Amyotroph Lateral Scler. (2009) 10:168-74. doi: 10.1080/17482960802603841

38. Agosta F, Rocca MA, Valsasina P, Sala S, Caputo D, Perini M, et al. A longitudinal diffusion tensor MRI study of the cervical cord and brain in amyotrophic lateral sclerosis patients. J Neurol Neurosurg Psychiatry. (2009) 80:53-5. doi: 10.1136/jnnp.2008.154252

39. Avants B, Khan A, McCluskey L, Elman L, Grossman M. Longitudinal cortical atrophy in amyotrophic lateral sclerosis with frontotemporal dementia. Arch Neurol. (2009) 66:138-9. doi: 10.1001/archneurol.2008.542

40. Lule D, Diekmann V, Kassubek J, Kurt A, Birbaumer N, Ludolph AC, et al. Cortical plasticity in amyotrophic lateral sclerosis: motor imagery and function. Neurorehabil Neural Repair. (2007) 21:518-26. doi: $10.1177 / 1545968307300698$

41. Unrath A, Ludolph AC, Kassubek J. Brain metabolites in definite amyotrophic lateral sclerosis. A longitudinal proton magnetic resonance spectroscopy study. J Neurol. (2007) 254:1099-106. doi: 10.1007/s00415-006-0495-2

42. Suhy J, Miller RG, Rule R Schuff N, Licht J, Dronsky V, et al. Early detection and longitudinal changes in amyotrophic lateral sclerosis by $1 \mathrm{H}$ MRSI. Neurology. (2002) 58:773-9. doi: 10.1212/WNL.58.5.773

43. Block W, Karitzky J, Träber F, Pohl C, Keller E, Mundegar RR, et al. Proton magnetic resonance spectroscopy of the primary motor cortex in patients with motor neuron disease: subgroup analysis and follow-up measurements. Arch Neurol. (1998) 55:931-6. doi: 10.1001/archneur.55.7.931

44. Irwin DJ, McMillan CT, Brettschneider J, Libon DJ, Powers J, Rascovsky $\mathrm{K}$, et al. Cognitive decline and reduced survival in C9orf72 expansion frontotemporal degeneration and amyotrophic lateral sclerosis. J Neurol Neurosurg Psychiatry. (2013) 84:163-9. doi: 10.1136/jnnp-2012-303507

45. Kolind S, Sharma R, Knight S, Johansen-Berg H, Talbot K, Turner MR. Myelin imaging in amyotrophic and primary lateral sclerosis. Amyotroph Lateral Scler Frontotemporal Degener. (2013) 14:562-73. doi: $10.3109 / 21678421.2013 .794843$

46. Verstraete E, Veldink JH, Hendrikse J, Schelhaas HJ, van den Heuvel MP, van den Berg LH. Structural MRI reveals cortical thinning in amyotrophic lateral sclerosis. J Neurol Neurosurg Psychiatry. (2012) 83:3838. doi: 10.1136/jnnp-2011-300909

47. Blain CR, Williams VC, Johnston C, Stanton BR, Ganesalingam J, Jarosz JM, et al. A longitudinal study of diffusion tensor MRI in ALS. Amyotroph Lateral Scler. (2007) 8:348-55. doi: 10.1080/17482960701548139

48. Rule RR, Suhy J, Schuff N, Gelinas DF, Miller RG, Weiner MW. Reduced NAA in motor and non-motor brain regions in amyotrophic lateral sclerosis: a cross-sectional and longitudinal study. Amyotroph Lateral Scler Other Motor Neuron Disord. (2004) 5:141-9. doi: 10.1080/14660820410017109

49. Escorcio-Bezerra ML, Abrahao A, Santos-Neto D, de Oliveira Braga NI, Oliveira ASB, Manzano GM. Why averaging multiple MUNIX measures in the longitudinal assessment of patients with ALS? Clin Neurophysiol. (2017) 128:2392-6. doi: 10.1016/j.clinph.2017.09.104

50. de Carvalho M, Swash M. Fasciculation potentials and earliest changes in motor unit physiology in ALS. J Neurol Neurosurg Psychiatry. (2013) 84:963-8. doi: 10.1136/jnnp-2012-304545

51. Boekestein WA, Schelhaas HJ, van Putten MJ, Stegeman DF, Zwarts MJ, van Dijk JP. Motor unit number index (MUNIX) versus motor unit number estimation (MUNE): a direct comparison in a longitudinal study of ALS patients. Clin Neurophysiol. (2012) 123:1644-9. doi: 10.1016/j.clinph.2012.01.004

52. Cheah BC, Lin CS, Park SB, Vucic S, Krishnan AV, Kiernan MC. Progressive axonal dysfunction and clinical impairment in amyotrophic lateral sclerosis. Clin Neurophysiol. (2012) 123:2460-7. doi: 10.1016/j.clinph.2012.06.020

53. Ahn S-W, Kim J-E, Sung J-J, Lee K-W, Hong Y-H. Asymmetry of motor unit number estimate and its rate of decline in patients with amyotrophic lateral sclerosis. J Clin Neurophysiol. (2011) 28:528-32. doi: 10.1097/WNP.0b013e318231c9e0

54. Cheah BC, Vucic S, Krishnan AV, Boland RA, Kiernan MC. Neurophysiological index as a biomarker for ALS progression: validity of mixed effects models. Amyotroph Lateral Scler. (2011) 12:33-8. doi: $10.3109 / 17482968.2010 .531742$ 
55. de Carvalho M, Swash M. Sensitivity of electrophysiological tests for upper and lower motor neuron dysfunction in ALS: a six-month longitudinal study. Muscle Nerve. (2010) 41:208-11. doi: 10.1002/mus.21495

56. Neuwirth C, Nandedkar S, Stalberg E, Weber M. Motor unit number index (MUNIX): a novel neurophysiological technique to follow disease progression in amyotrophic lateral sclerosis. Muscle Nerve. (2010) 42:379-84. doi: $10.1002 /$ mus.21707

57. Floyd AG, Yu QP, Piboolnurak P, Tang MX, Fang Y, Smith WA, et al. Transcranial magnetic stimulation in ALS: utility of central motor conduction tests. Neurology. (2009) 72:498-504. doi: 10.1212/01.wnl.0000341933.97883.a4

58. Gooch CL, Pullman SL, Shungu DC, Ulug AM, Chan S, Gordon PH, et al. Motor unit number estimation (MUNE) in diseases of the motor neuron: utility and comparative analysis in a multimodal biomarker study. Suppl Clin Neurophysiol. (2009) 60:153-62. doi: 10.1016/S1567-424X(08)00015-9

59. Liu XX, Zhang J, Zheng JY, Zhang S, Xu YS, Kang DX, et al. Stratifying disease stages with different progression rates determined by electrophysiological tests in patients with amyotrophic lateral sclerosis. Muscle Nerve. (2009) 39:304-9. doi: 10.1002/mus.21144

60. Albrecht E, Kuntzer T. Number of Edb motor units estimated using an adapted multiple point stimulation method: normal values and longitudinal studies in ALS and peripheral neuropathies. Clin Neurophysiol. (2004) 115:557-63. doi: 10.1016/j.clinph.2003.11.001

61. Wang FC, Bouquiaux O, De Pasqua V, Delwaide PJ. Changes in motor unit numbers in patients with ALS: a longitudinal study using the adapted multiple point stimulation method. Amyotroph Lateral Scler Other Motor Neuron Disord. (2002) 3:31-8. doi: 10.1080/146608202317576516

62. Chan KM, Stashuk DW, Brown WF. A longitudinal study of the pathophysiological changes in single human thenar motor units in amyotrophic lateral sclerosis. Muscle Nerve. (1998) 21:1714-23.

63. Felice KJ. A longitudinal study comparing thenar motor unit number estimates to other quantitative tests in patients with amyotrophic lateral sclerosis. Muscle Nerve. (1997) 20:179-85.

64. Yuen EC, Olney RK. Longitudinal study of fiber density and motor unit number estimate in patients with amyotrophic lateral sclerosis. Neurology. (1997) 49:573-8. doi: 10.1212/WNL.49.2.573

65. Vucic S, Lin CS, Cheah BC, Murray J, Menon P, Krishnan AV, et al. Riluzole exerts central and peripheral modulating effects in amyotrophic lateral sclerosis. Brain. (2013) 136(Pt 5):1361-70. doi: 10.1093/brain/awt085

66. Aggarwal A, Nicholson G. Detection of preclinical motor neurone loss in SOD1 mutation carriers using motor unit number estimation. J Neurol Neurosurg Psychiatry. (2002) 73:199-201. doi: 10.1136/jnnp.73.2.199

67. Arasaki K, Kato Y, Hyodo A, Ushijima R, Tamaki M. Longitudinal study of functional spinal alpha motor neuron loss in amyotrophic lateral sclerosis. Muscle Nerve. (2002) 25:520-6. doi: 10.1002/mus.10067

68. de Carvalho M, Miranda PC, Luis ML, Ducla-Soares E. Cortical muscle representation in amyotrophic lateral sclerosis patients: changes with disease evolution. Muscle Nerve. (1999) 22:1684-92.

69. Swash M, Schwartz MS. A longitudinal study of changes in motor units in motor neuron disease. J Neurol Sci. (1982) 56:185-97. doi: 10.1016/0022-510X(82)90141-1

70. Thakore NJ, Lapin BR, Pioro EP. Trajectories of impairment in amyotrophic lateral sclerosis: insights from the pooled resource open-access ALS clinical trials cohort. Muscle Nerve. (2018) 57:937-45. doi: 10.1002/mus.26042

71. Rooney J, Burke T, Vajda A, Heverin M, Hardiman O. What does the ALSFRS-R really measure? A longitudinal and survival analysis of functional dimension subscores in amyotrophic lateral sclerosis. J Neurol Neurosurg Psychiatry. (2016) 88:381-5. doi: 10.1136/jnnp-2016-314661

72. The amyotrophic lateral sclerosis functional rating scale. Assessment of activities of daily living in patients with amyotrophic lateral sclerosis. The ALS CNTF treatment study (ACTS) phase I-II Study Group. Arch Neurol. (1996) 53:141-7. doi: 10.1001/archneur.1996.00550020045014

73. Floeter MK, Traynor BJ, Farren J, Braun LE, Tierney M, Wiggs EA, et al. Disease progression in C9orf72 mutation carriers. Neurology. (2017) 89:23441. doi: 10.1212/WNL.0000000000004115

74. Elamin M, Bede P, Byrne S, Jordan N, Gallagher L, Wynne B, et al. Cognitive changes predict functional decline in ALS: a population-based longitudinal study. Neurology. (2013) 80:1590-7. doi: 10.1212/WNL.0b013e31828f18ac
75. Roberts-South A, Findlater K, Strong MJ, Orange JB. Longitudinal changes in discourse production in amyotrophic lateral sclerosis. Semin Speech Lang. (2012) 33:79-94. doi: 10.1055/s-0031-1301165

76. Duning T, Schiffbauer H, Warnecke T, Mohammadi S, Floel A, Kolpatzik K, et al. G-CSF prevents the progression of structural disintegration of white matter tracts in amyotrophic lateral sclerosis: a pilot trial. PLOS ONE. (2011) 6:e17770. doi: 10.1371/journal.pone.0017770

77. Poletti B, Solca F, Carelli L, Faini A, Madotto F, Lafronza A, et al. Cognitivebehavioral longitudinal assessment in ALS: the Italian Edinburgh Cognitive and Behavioral ALS screen (ECAS). Amyotroph Lateral Scler Frontotemporal Degener. (2018) 19:387-95. doi: 10.1080/21678421.2018.1473443

78. Xu Z, Alruwaili ARS, Henderson RD, McCombe PA. Screening for cognitive and behavioural impairment in amyotrophic lateral sclerosis: frequency of abnormality and effect on survival. J Neurol Sci. (2017) 376:16-23. doi: 10.1016/j.jns.2017.02.061

79. Gillingham SM, Yunusova Y, Ganda A, Rogaeva E, Black SE, Stuss DT, et al. Assessing cognitive functioning in ALS: a focus on frontal lobe processes. Amyotroph Lateral Scler Frontotemporal Degener. (2017) 18:18292. doi: 10.1080/21678421.2016.1248977

80. Mioshi E, Hsieh S, Caga J, Ramsey E, Chen K, Lillo P, et al. A novel tool to detect behavioural symptoms in ALS. Amyotroph Lateral Scler Frontotemporal Degener. (2014) 15:298-304. doi: $10.3109 / 21678421.2014 .896927$

81. Jakobsson Larsson B, Ozanne AG, Nordin K, Nygren I. A prospective study of quality of life in amyotrophic lateral sclerosis patients. Acta Neurol Scand. (2017) 136:631-8. doi: 10.1111/ane.12774

82. Beck M, Giess R, Magnus T, Puls I, Reiners K, Toyka KV, et al. Progressive sudomotor dysfunction in amyotrophic lateral sclerosis. J Neurol Neurosurg Psychiatry. (2002) 73:68-70. doi: 10.1136/jnnp.73.1.68

83. Garruto RM, Plato CC, Yanagihara R, Fox K, Dutt J, Gajdusek DC, et al. Bone mass in Guamanian patients with amyotrophic lateral sclerosis and parkinsonism-dementia. Am J Phys Anthropol. (1989) 80:107-13. doi: 10.1002/ajpa.1330800112

84. Ioannides ZA, Steyn FJ, Henderson RD, McCombe PA, Ngo ST. Anthropometric measures are not accurate predictors of fat mass in ALS. Amyotroph Lateral Scler Frontotemporal Degener. (2017) 18:486-91. doi: 10.1080/21678421.2017.1317811

85. Peter RS, Rosenbohm A, Dupuis L, Brehme T, Kassubek J, Rothenbacher D, et al. Life course body mass index and risk and prognosis of amyotrophic lateral sclerosis: results from the ALS registry Swabia. Eur J Epidemiol. (2017) 32:901-8. doi: 10.1007/s10654-017-0318-z

86. Nunes G, Santos CA, Grunho M, Fonseca J. Enteral feeding through endoscopic gastrostomy in amyotrophic lateral sclerosis patients. Nutr Hosp. (2016) 33:561. doi: 10.20960/nh.561

87. Jablecki CK, Berry C, Leach J. Survival prediction in amyotrophic lateral sclerosis. Muscle Nerve. (1989) 12:833-41. doi: 10.1002/mus. 880121008

88. Andres PL, Allred MP, Stephens HE, Proffitt Bunnell M, Siener C, Macklin EA, et al. Fixed dynamometry is more sensitive than vital capacity or ALS rating scale. Muscle Nerve. (2017) 56:710-5. doi: 10.1002/ mus. 25586

89. de Bie E, Oskarsson B, Joyce NC, Nicorici A, Kurillo G, Han JJ. Longitudinal evaluation of upper extremity reachable workspace in ALS by Kinect sensor. Amyotroph Lateral Scler Frontotemporal Degener. (2017) 18:17-23. doi: 10.1080/21678421.2016.1241278

90. Shellikeri S, Green JR, Kulkarni M, Rong P, Martino R, Zinman L, et al. Speech movement measures as markers of bulbar disease in amyotrophic lateral sclerosis. J Speech Lang Hear Res. (2016) 59:887-99. doi: 10.1044/2016_JSLHR-S-15-0238

91. Londral A, Pinto S, de Carvalho M. Markers for upper limb dysfunction in Amyotrophic Lateral Sclerosis using analysis of typing activity. Clin Neurophysiol. (2016) 127:925-31. doi: 10.1016/j.clinph.2015.06.017

92. Panitz S, Kornhuber M, Hanisch F. The checklist individual strength (CIS20R) in patients with amyotrophic lateral sclerosis - a longitudinal study. Acta Neurol Scand. (2015) 131:372-80. doi: 10.1111/ane.12349

93. Atassi N, Berry J, Shui A, Zach N, Sherman A, Sinani E, et al. The PRO-ACT database: design, initial analyses, and predictive features. Neurology. (2014) 83:1719-25. doi: 10.1212/WNL.0000000000000951 
94. Watanabe H, Atsuta N, Nakamura R, Hirakawa A, Watanabe H, Ito M, et al. Factors affecting longitudinal functional decline and survival in amyotrophic lateral sclerosis patients. Amyotroph Lateral Scler Frontotemporal Degener. (2015) 16:230-6. doi: 10.3109/21678421.2014.990036

95. Leonardis L, Dolenc Groselj L, Vidmar G. Factors related to respiration influencing survival and respiratory function in patients with amyotrophic lateral sclerosis: a retrospective study. Eur J Neurol. (2012) 19:1518-24. doi: 10.1111/j.1468-1331.2012.03754.x

96. Mahajan KR, Bach JR, Saporito L, Perez N. Diaphragm pacing and noninvasive respiratory management of amyotrophic lateral sclerosis/motor neuron disease. Muscle Nerve. (2012) 46:851-5. doi: 10.1002/mus.23663

97. Pinto S, Geraldes R, Vaz N, Pinto A, de Carvalho M. Changes of the phrenic nerve motor response in amyotrophic lateral sclerosis: longitudinal study. Clin Neurophysiol. (2009) 120:2082-5. doi: 10.1016/j.clinph.2009.08.025

98. Montes J, Cheng B, Diamond B, Doorish C, Mitsumoto H, Gordon PH. The Timed Up and Go test: predicting falls in ALS. Amyotroph Lateral Scler. (2007) 8:292-5. doi: 10.1080/17482960701435931

99. Vender RL, Mauger D, Walsh S, Alam S, Simmons Z. Respiratory systems abnormalities and clinical milestones for patients with amyotrophic lateral sclerosis with emphasis upon survival. Amyotroph Lateral Scler. (2007) 8:36-41. doi: 10.1080/17482960600863951

100. Wilson SR, Quantz MA, Strong MJ, Ahmad D. Increasing peak expiratory flow time in amyotrophic lateral sclerosis. Chest. (2005) 127:156-60. doi: $10.1378 /$ chest.127.1.156

101. Poloni M, Mento SA, Mascherpa C, Ceroni M. Value of spirometric investigations in amyotrophic lateral sclerosis. Ital J Neurol Sci. (1983) 4:39-46. doi: 10.1007/BF02043436

102. Andersen TM, Sandnes A, Fondenes O, Nilsen RM, Tysnes OB, Heimdal JH, et al. Laryngeal responses to mechanically assisted cough in progressing amyotrophic lateral sclerosis. Respir Care. (2018) 63:538-49. doi: $10.4187 /$ respcare.05924

103. Quaranta VN, Carratu P, Damiani MF, Dragonieri S, Capozzolo A, Cassano A, et al. The prognostic role of obstructive sleep apnea at the onset of amyotrophic lateral sclerosis. Neurodegener Dis. (2017) 17:14-21. doi: 10.1159/000447560

104. Proudfoot M, Menke RA, Sharma R, Berna CM, Hicks SL, Kennard C, et al. Eye-tracking in amyotrophic lateral sclerosis: a longitudinal study of saccadic and cognitive tasks. Amyotroph Lateral Scler Frontotemporal Degener. (2015) 17:101-11. doi: 10.3109/21678421.2015.1054292

105. Lenglet T, Lacomblez L, Abitbol JL, Ludolph A, Mora JS, Robberecht W, et al. A phase II-III trial of olesoxime in subjects with amyotrophic lateral sclerosis. Eur J Neurol. (2014) 21:529-36. doi: 10.1111/ene.12344

106. Yamauchi R, Imai $T$, Tsuda E, Hozuki T, Yamamoto D, Shimohama S. Respiratory insufficiency with preserved diaphragmatic function in amyotrophic lateral sclerosis. Intern Med. (2014) 53:1325-31. doi: 10.2169/internalmedicine.53.2326

107. Mendoza M, Gelinas DF, Moore DH, Miller RG. A comparison of maximal inspiratory pressure and forced vital capacity as potential criteria for initiating non-invasive ventilation in amyotrophic lateral sclerosis. Amyotroph Lateral Scler. (2007) 8:106-11. doi: 10.1080/17482960601030188

108. Marti-Fabregas J, Dourado M, Sanchis J, Miralda R, Pradas J, Illa I. Respiratory function deterioration is not time-linked with upper-limb onset in amyotrophic lateral sclerosis. Acta Neurol Scand. (1995) 92:261-4. doi: 10.1111/j.1600-0404.1995.tb01699.x

109. Palmowski A, Jost WH, Prudlo J, Osterhage J, Kasmann B, Schimrigk K, et al. Eye movement in amyotrophic lateral sclerosis: a longitudinal study. Ger J Ophthalmol. (1995) 4:355-62.

110. El Mendili MM, Chen R, Tiret B, Villard N, Trunet S, Pelegrini-Issac M, et al. Fast and accurate semi-automated segmentation method of spinal cord MR images at $3 \mathrm{~T}$ applied to the construction of a cervical spinal cord template. PLoS ONE. (2015) 10:e0122224. doi: 10.1371/journal.pone.0122224

111. Cohen-Adad J, El Mendili MM, Morizot-Koutlidis R, Lehericy S, Meininger V, Blancho S, et al. Involvement of spinal sensory pathway in ALS and specificity of cord atrophy to lower motor neuron degeneration. Amyotroph Lateral Scler Frontotemporal Degener. (2013) 14:30-8. doi: 10.3109/17482968.2012.701308

112. Bede P, Bokde AL, Byrne S, Elamin M, Fagan AJ, Hardiman O. Spinal cord markers in ALS: diagnostic and biomarker considerations.
Amyotroph Lateral Scler. (2012) 13:407-15. doi: 10.3109/17482968.20 11.649760

113. El Mendili MM, Cohen-Adad J, Pelegrini-Issac M, Rossignol S, MorizotKoutlidis R, Marchand-Pauvert V, et al. Multi-parametric spinal cord MRI as potential progression marker in amyotrophic lateral sclerosis. PLoS ONE. (2014) 9:e95516. doi: 10.1371/journal.pone.0095516

114. Querin G, El Mendili MM, Bede P, Delphine S, Lenglet T, MarchandPauvert V, et al. Multimodal spinal cord MRI offers accurate diagnostic classification in ALS. J Neurol Neurosurg Psychiatry. (2018) 89:1220-1. doi: 10.1136/jnnp-2017-317214

115. Querin G, El Mendili MM, Lenglet T, Delphine S, Marchand-Pauvert V, Benali $\mathrm{H}$, et al. Spinal cord multi-parametric magnetic resonance imaging for survival prediction in amyotrophic lateral sclerosis. Eur J Neurol. (2017) 24:1040-6. doi: 10.1111/ene.13329

116. Grolez G, Moreau C, Danel-Brunaud V, Delmaire C, Lopes R, Pradat $\mathrm{PF}$, et al. The value of magnetic resonance imaging as a biomarker for amyotrophic lateral sclerosis: a systematic review. BMC Neurol. (2016) 16:155. doi: 10.1186/s12883-016-0672-6

117. Stroman PW, Wheeler-Kingshott C, Bacon M, Schwab JM, Bosma R, Brooks $\mathrm{J}$, et al. The current state-of-the-art of spinal cord imaging: methods. NeuroImage. (2014) 84:1070-81. doi: 10.1016/j.neuroimage.2013.04.124

118. Verma T, Cohen-Adad J. Effect of respiration on the $\mathrm{B} 0$ field in the human spinal cord at 3T. Magn Reson Med. (2014) 72:1629-36. doi: 10.1002/mrm.25075

119. Finegan E, Chipika RH, Shing SLH, Hardiman O, Bede P. Primary lateral sclerosis: a distinct entity or part of the ALS spectrum? Amyotroph Lateral Scler Frontotemporal Degener. 2019:1-13. doi: 10.1080/21678421.2018.1550518

120. Bede P, Querin G, Pradat PF. The changing landscape of motor neuron disease imaging: the transition from descriptive studies to precision clinical tools. Curr Opin Neurol. (2018) 31:431-8. doi: 10.1097/WCO.0000000000000569

121. Muller HP, Turner MR, Grosskreutz J, Abrahams S, Bede P, Govind V, et al. A large-scale multicentre cerebral diffusion tensor imaging study in amyotrophic lateral sclerosis. J Neurol Neurosurg Psychiatry. (2016) 87:5709. doi: 10.1136/jnnp-2015-311952

122. Atassi N, Xu M, Triantafyllou C, Keil B, Lawson R, Cernasov P, et al. Ultra high-field (7tesla) magnetic resonance spectroscopy in Amyotrophic Lateral Sclerosis. PLoS ONE. (2017) 12:e0177680. doi: 10.1371/journal.pone.0177680

123. Verstraete E, Biessels GJ, van Den Heuvel MP, Visser F, Luijten PR, van Den Berg LH. No evidence of microbleeds in ALS patients at 7 Tesla MRI. Amyotroph Lateral Scler. (2010) 11:555-7. doi: 10.3109/17482968.2010.513053

124. Dimond D, Ishaque A, Chenji S, Mah D, Chen Z, Seres P, et al. White matter structural network abnormalities underlie executive dysfunction in amyotrophic lateral sclerosis. Hum Brain Mapp. (2017) 38:1249-68. doi: $10.1002 / \mathrm{hbm} .23452$

125. Cardenas AM, Sarlls JE, Kwan JY, Bageac D, Gala ZS, Danielian LE, et al. Pathology of callosal damage in ALS: an ex-vivo, $7 \mathrm{~T}$ diffusion tensor MRI study. NeuroImage Clin. (2017) 15:200-8. doi: 10.1016/j.nicl. 2017.04.024

126. De Reuck J, Devos D, Moreau C, Auger F, Durieux N, Deramecourt V, et al. Topographic distribution of brain iron deposition and small cerebrovascular lesions in amyotrophic lateral sclerosis and in frontotemporal lobar degeneration: a post-mortem 7.0-tesla magnetic resonance imaging study with neuropathological correlates. Acta Neurol Belg. (2017) 117:873-8. doi: 10.1007/s13760-017-0832-5

127. Pugdahl K, Fuglsang-Frederiksen A, Johnsen B, Tankisi H, de Carvalho $\mathrm{M}$, Fawcett PRW, et al. Variation in the neurophysiological examination of amyotrophic lateral sclerosis in Europe. Amyotroph Lateral Scler. (2010) 11:443-8. doi: 10.3109/17482960903552496

128. Cedarbaum JM, Stambler N, Malta E, Fuller C, Hilt D, Thurmond B, et al. The ALSFRS-R: a revised ALS functional rating scale that incorporates assessments of respiratory function. BDNF ALS Study Group (Phase III). J Neurol Sci. (1999) 169:13-21.

129. Petrov D, Mansfield C, Moussy A, Hermine O. ALS clinical trials review: 20 Years of failure. Are we any closer to registering a new treatment? Front Aging Neurosci. (2017) 9:68. doi: 10.3389/fnagi.2017.00068 
130. Jenkinson C, Harris R, Fitzpatrick R. The Amyotrophic Lateral Sclerosis Assessment Questionnaire (ALSAQ-40): evidence for a method of imputing missing data. Amyotroph Lateral Scler. (2007) 8:90-5. doi: 10.1080/17482960600989343

131. Aggarwal SP, Zinman L, Simpson E, McKinley J, Jackson KE, Pinto $\mathrm{H}$, et al. Safety and efficacy of lithium in combination with riluzole for treatment of amyotrophic lateral sclerosis: a randomised, doubleblind, placebo-controlled trial. Lancet Neurology. (2010) 9:481-8. doi: 10.1016/S1474-4422(10)70068-5

132. Smith R, Pioro E, Myers K, Sirdofsky M, Goslin K, Meekins G, et al. Enhanced bulbar function in amyotrophic lateral sclerosis: the nuedexta treatment trial. Neurotherapeutics. (2017) 14:762-72. doi: 10.1007/s13311-016-0508-5

133. Woo JH, Wang S, Melhem ER, Gee JC, Cucchiara A, McCluskey L, et al. Linear associations between clinically assessed upper motor neuron disease and diffusion tensor imaging metrics in amyotrophic lateral sclerosis. PLoS ONE. (2014) 9:e105753. doi: 10.1371/journal.pone.0105753

134. Cudkowicz ME, Titus S, Kearney M, Yu H, Sherman A, Schoenfeld D, et al. Efficacy and safety of ceftriaxone for amyotrophic lateral sclerosis: results of a multi-stage, randomised, double-blind, placebo-controlled, phase 3 study. Lancet Neurology. (2014) 13:1083-91. doi: 10.1016/S1474-4422(14)70222-4

135. Bensimon G, Lacomblez L, Meininger V. A controlled trial of riluzole in amyotrophic lateral sclerosis. ALS/Riluzole Study Group. N Engl J Med. (1994) 330:585-91. doi: 10.1056/NEJM199403033300901

136. Kim S, Kim JK, Son MJ, Kim D, Song B, Son I, et al. Mecasin treatment in patients with amyotrophic lateral sclerosis: study protocol for a randomized controlled trial. Trials. (2018) 19:225. doi: 10.1186/s13063-018-2557-Z

137. Shefner JM, Liu D, Leitner ML, Schoenfeld D, Johns DR, Ferguson T, et al. Quantitative strength testing in ALS clinical trials. Neurology. (2016) 87:617-24. doi: 10.1212/WNL.0000000000002941

138. Berry JD, Paganoni S, Atassi N, Macklin EA, Goyal N, Rivner M, et al. Phase IIa trial of fingolimod for amyotrophic lateral sclerosis demonstrates acceptable acute safety and tolerability. Muscle Nerve. (2017) 56:1077-84. doi: $10.1002 /$ mus. 25733

139. Jawaid A, Murthy SB, Wilson AM, Qureshi SU, Amro MJ, Wheaton M, et al. A decrease in body mass index is associated with faster progression of motor symptoms and shorter survival in ALS. Amyotroph Lateral Scler. (2010) 11:542-8. doi: 10.3109/17482968.2010.482592

140. Calvo A, Moglia C, Lunetta C, Marinou K, Ticozzi N, Ferrante GD, et al. Factors predicting survival in ALS: a multicenter Italian study. J Neurol. (2017) 264:54-63. doi: 10.1007/s00415-016-8313-y

141. Abrahams S, Newton J, Niven E, Foley J, Bak TH. Screening for cognition and behaviour changes in ALS. Amyotroph Lateral Scler Frontotemporal Degener. (2014) 15:9-14. doi: 10.3109/21678421.2013.805784

142. Elamin M, Pinto-Grau M, Burke T, Bede P, Rooney J, O'Sullivan M, et al. Identifying behavioural changes in ALS: validation of the Beaumont Behavioural Inventory (BBI). Amyotroph Lateral Scler Frontotemporal Degener. (2016) 8:68-73. doi: 10.1080/21678421.2016.1248976

143. Woolley SC, York MK, Moore DH, Strutt AM, Murphy J, Schulz PE, et al. Detecting frontotemporal dysfunction in ALS: utility of the ALS Cognitive Behavioral Screen (ALS-CBS). Amyotroph Lateral Scler. (2010) 11:303-11. doi: 10.3109/17482961003727954

144. Byrne S, Elamin M, Bede P, Shatunov A, Walsh C, Corr B, et al. Cognitive and clinical characteristics of patients with amyotrophic lateral sclerosis carrying a C9orf72 repeat expansion: a population-based cohort study. Lancet Neurol. (2012) 11:232-40. doi: 10.1016/S1474-4422(12)70014-5

145. Bede P, Bokde ALW, Byrne S, Elamin M, McLaughlin RL, Kenna K, et al. Multiparametric MRI study of ALS stratified for the C9orf72 genotype. Neurology. (2013) 81:361-9. doi: 10.1212/WNL.0b013 e31829c5eee

146. Christidi F, Karavasilis E, Rentzos M, Kelekis N, Evdokimidis I, Bede P. Clinical and radiological markers of extra-motor deficits in amyotrophic lateral sclerosis. Front Neurol. (2018) 9:1005. doi: 10.3389/fneur.2018.01005

147. Burkhardt C, Neuwirth C, Weber M. Longitudinal assessment of the Edinburgh Cognitive and Behavioural Amyotrophic Lateral Sclerosis Screen (ECAS): lack of practice effect in ALS patients? Amyotroph Lateral Scler Frontotemporal Degener. (2017) 18:202-9. doi: $10.1080 / 21678421.2017 .1283418$
148. Kasper E, Zydatiss K, Schuster C, Machts J, Bittner D, Kaufmann $J$, et al. No change in executive performance in ALS patients: a longitudinal neuropsychological study. Neurodegener Dis. (2016) 16:184-91. doi: 10.1159/000440957

149. Woolley S, Goetz R, Factor-Litvak P, Murphy J, Hupf J, LomenHoerth C, et al. Longitudinal screening detects cognitive stability and behavioral deterioration in ALS patients. Behav Neurol. (2018) 2018:5969137. doi: $10.1155 / 2018 / 5969137$

150. Okada M, Yamashita S, Ueyama H, Ishizaki M, Maeda Y, Ando Y. Long-term effects of edaravone on survival of patients with amyotrophic lateral sclerosis. eNeurologicalSci. (2018) 11:11-4. doi: 10.1016/j.ensci.2018.05.001

151. Raheja R, Regev K, Healy BC, Mazzola MA, Beynon V, Von Glehn F, et al. Correlating serum micrornas and clinical parameters in amyotrophic lateral sclerosis. Muscle Nerve. (2018) 58:261-9. doi: 10.1002/mus.26106

152. Thompson AG, Gray E, Thezenas ML, Charles PD, Evetts S, Hu MT, et al. Cerebrospinal fluid macrophage biomarkers in amyotrophic lateral sclerosis. Ann Neurol. (2018) 83:258-68. doi: 10.1002/ana.25143

153. Di Pietro L, Baranzini M, Berardinelli MG, Lattanzi W, Monforte M, Tasca G, et al. Potential therapeutic targets for ALS: MIR206, MIR208b and MIR499 are modulated during disease progression in the skeletal muscle of patients. Sci Rep. (2017) 7:9538. doi: 10.1038/s41598-017-10161-Z

154. Murdock BJ, Zhou T, Kashlan SR, Little RJ, Goutman SA, Feldman EL. Correlation of peripheral immunity with rapid amyotrophic lateral sclerosis progression. JAMA Neurol. (2017) 74:1446-54. doi: 10.1001/jamaneurol.2017.2255

155. Shepheard SR, Wuu J, Cardoso M, Wiklendt L, Dinning PG, Chataway $\mathrm{T}$, et al. Urinary p75(ECD): a prognostic, disease progression, and pharmacodynamic biomarker in ALS. Neurology. (2017) 88:1137-43. doi: 10.1212/WNL.0000000000003741

156. van Eijk RPA, Eijkemans MJC, Ferguson TA, Nikolakopoulos S, Veldink JH, van den Berg LH. Monitoring disease progression with plasma creatinine in amyotrophic lateral sclerosis clinical trials. J Neurol Neurosurg Psychiatry. (2018) 89:156-61. doi: 10.1136/jnnp-2017-317077

157. Waller R, Goodall EF, Milo M, Cooper-Knock J, Da Costa M, Hobson E, et al. Serum miRNAs miR-206, 143-3p and 374b-5p as potential biomarkers for amyotrophic lateral sclerosis (ALS). Neurobiol Aging. (2017) 55:123-31. doi: 10.1016/j.neurobiolaging.2017.03.027

158. McCombe PA, Pfluger C, Singh P, Lim CY, Airey C, Henderson RD. Serial measurements of phosphorylated neurofilament-heavy in the serum of subjects with amyotrophic lateral sclerosis. J Neurol Sci. (2015) 353:122-9. doi: 10.1016/j.jns.2015.04.032

159. Lu CH, Petzold A, Topping J, Allen K, Macdonald-Wallis C, Clarke J, et al. Plasma neurofilament heavy chain levels and disease progression in amyotrophic lateral sclerosis: insights from a longitudinal study. J Neurol Neurosurg Psychiatry. (2015) 86:565-73. doi: 10.1136/jnnp-2014-307672

160. Levine TD, Bowser R, Hank NC, Gately S, Stephan D, Saperstein DS, et al. A pilot trial of pioglitazone $\mathrm{HCl}$ and tretinoin in ALS: cerebrospinal fluid biomarkers to monitor drug efficacy and predict rate of disease progression. Neurol Res Int. (2012) 2012:582075. doi: 10.1155/2012/582075

161. Levine TD, Bowser R, Hank N, Saperstein D. A pilot trial of memantine and riluzole in ALS: correlation to CSF biomarkers. Amyotroph Lateral Scler. (2010) 11:514-9. doi: 10.3109/17482968.2010.513052

162. Wilson ME, Boumaza I, Lacomis D, Bowser R. Cystatin C: a candidate biomarker for amyotrophic lateral sclerosis. PLoS ONE. (2010) 5:e15133. doi: 10.1371/journal.pone.0015133

163. Gaiani A, Martinelli I, Bello L, Querin G, Puthenparampil M, Ruggero $S$, et al. Diagnostic and prognostic biomarkers in amyotrophic lateral sclerosis: neurofilament light chain levels in definite subtypes of disease. JAMA Neurol. (2017) 74:525-32. doi: 10.1001/jamaneurol. 2016.5398

164. Lu CH, Allen K, Oei F, Leoni E, Kuhle J, Tree T, et al. Systemic inflammatory response and neuromuscular involvement in amyotrophic lateral sclerosis. Neurol Neuroimmunol Neuroinflamm. (2016) 3:e244. doi: 10.1212/NXI.0000000000000244

165. Steinacker P, Feneberg E, Weishaupt J, Brettschneider J, Tumani H, Andersen PM, et al. Neurofilaments in the diagnosis of motoneuron diseases: a prospective study on 455 patients. J Neurol Neurosurg Psychiatry. (2016) 87:12-20. doi: 10.1136/jnnp-2015-311387 
166. Gibson SB, Kasarskis EJ, Hu N, Pulst SM, Mendiondo MS, Matthews $\mathrm{DE}$, et al. Relationship of creatine kinase to body composition, disease state, and longevity in ALS. Amyotroph Lateral Scler Frontotemporal Degener. (2015) 16:473-7. doi: 10.3109/21678421.2015. 1062516

167. Gray E, Larkin JR, Claridge TD, Talbot K, Sibson NR, Turner MR. The longitudinal cerebrospinal fluid metabolomic profile of amyotrophic lateral sclerosis. Amyotroph Lateral Scler Frontotemporal Degener. (2015) 16:45663. doi: $10.3109 / 21678421.2015 .1053490$

168. Lu CH, Macdonald-Wallis C, Gray E, Pearce N, Petzold A, Norgren $\mathrm{N}$, et al. Neurofilament light chain: a prognostic biomarker in amyotrophic lateral sclerosis. Neurology. (2015) 84:2247-57. doi: 10.1212/WNL.0000000000001642

169. Verstraete E, Kuiperij HB, van Blitterswijk MM, Veldink JH, Schelhaas $\mathrm{HJ}$, van den Berg LH, et al. TDP-43 plasma levels are higher in amyotrophic lateral sclerosis. Amyotroph Lateral Scler. (2012) 13:446-51. doi: 10.3109/17482968.2012.703208

170. Nardo G, Pozzi S, Pignataro M, Lauranzano E, Spano G, Garbelli $\mathrm{S}$, et al. Amyotrophic lateral sclerosis multiprotein biomarkers in peripheral blood mononuclear cells. PLoS ONE. (2011) 6:e25545. doi: 10.1371/journal.pone. 0025545

171. Steinacker P, Huss A, Mayer B, Grehl T, Grosskreutz J, Borck G, et al. Diagnostic and prognostic significance of neurofilament light chain NF-L, but not progranulin and S100B, in the course of amyotrophic lateral sclerosis: data from the German MND-net. Amyotroph Lateral Scler Frontotemporal Degener. (2017) 18:112-9. doi: 10.1080/21678421.2016.1241279

172. Blasco H, Patin F, Descat A, Garcon G, Corcia P, Gele P, et al. A pharmaco-metabolomics approach in a clinical trial of ALS: identification of predictive markers of progression. PLoS ONE. (2018) 13:e0198116. doi: 10.1371/journal.pone.0198116

173. Masaldan S, Bush AI, Devos D, Rolland AS, Moreau C. Striking while the iron is hot: iron metabolism and ferroptosis in neurodegeneration. Free Radic Biol Med. (2018) 133:221-33. doi: 10.1016/j.freeradbiomed.2018.09.033

174. Van Weemen BK, Schuurs AH. Immunoassay using antigenenzyme conjugates. FEBS Lett. (1971) 15:232-6. doi: 10.1016/00145793(71)80319-8

175. Boylan K, Yang C, Crook J, Overstreet K, Heckman M, Wang Y, et al. Immunoreactivity of the phosphorylated axonal neurofilament $\mathrm{H}$ subunit (pNF-H) in blood of ALS model rodents and ALS patients: evaluation of blood pNF-H as a potential ALS biomarker. J Neurochem. (2009) 111:118291. doi: 10.1111/j.1471-4159.2009.06386.x

176. Reijn TS, Abdo WF, Schelhaas HJ, Verbeek MM. CSF neurofilament protein analysis in the differential diagnosis of ALS. J Neurol. (2009) 256:615-9. doi: 10.1007/s00415-009-0131-z

177. Strong MJ, Kesavapany S, Pant HC. The pathobiology of amyotrophic lateral sclerosis: a proteinopathy? J Neuropathol Exp Neurol. (2005) 64:649-64. doi: 10.1097/01.jnen.0000173889.71434.ea

178. Ranganathan S, Williams E, Ganchev P, Gopalakrishnan V, Lacomis D, Urbinelli L, et al. Proteomic profiling of cerebrospinal fluid identifies biomarkers for amyotrophic lateral sclerosis. J Neurochem. (2005) 95:146171. doi: 10.1111/j.1471-4159.2005.03478.x

179. Ryberg H, An J, Darko S, Lustgarten JL, Jaffa M, Gopalakrishnan $\mathrm{V}$, et al. Discovery and verification of amyotrophic lateral sclerosis biomarkers by proteomics. Muscle Nerve. (2010) 42:104-11. doi: 10.1002/ mus. 21683

180. Pasinetti GM, Ungar LH, Lange DJ, Yemul S, Deng H, Yuan X, et al. Identification of potential CSF biomarkers in ALS. Neurology. (2006) 66:1218. doi: 10.1212/01.wnl.0000203129.82104.07

181. Menke RA, Proudfoot M, Wuu J, Andersen PM, Talbot K, Benatar M, et al. Increased functional connectivity common to symptomatic amyotrophic lateral sclerosis and those at genetic risk. J Neurol Neurosurg Psychiatry. (2016) 87:580-8. doi: 10.1136/jnnp-2015-311945

182. Carew JD, Nair G, Andersen PM, Wuu J, Gronka S, Hu X, et al. Presymptomatic spinal cord neurometabolic findings in SOD1positive people at risk for familial ALS. Neurology. (2011) 77:1370-5. doi: 10.1212/WNL.0b013e318231526a

183. Lee SE, Sias AC, Mandelli ML, Brown JA, Brown AB, Khazenzon $\mathrm{AM}$, et al. Network degeneration and dysfunction in presymptomatic
C9ORF72 expansion carriers. NeuroImage Clin. (2017) 14:286-97. doi: 10.1016/j.nicl.2016.12.006

184. Ng MC, Ho JT, Ho SL, Lee R, Li G, Cheng TS, et al. Abnormal diffusion tensor in nonsymptomatic familial amyotrophic lateral sclerosis with a causative superoxide dismutase 1 mutation. J Magn Reson Imaging. (2008) 27:8-13. doi: $10.1002 / j m r i .21217$

185. Wen J, Zhang H, Alexander DC, Durrleman S, Routier A, Rinaldi D, et al. Neurite density is reduced in the presymptomatic phase of C9orf72 disease. $J$ Neurol Neurosurg Psychiatry. (2018). doi: 10.1136/jnnp-2018-318994. [Epub ahead of print].

186. Bertrand A, Wen J, Rinaldi D, Houot M, Sayah S, Camuzat A, et al. Early cognitive, structural, and microstructural changes in presymptomatic C9orf72 carriers younger than 40 Years. JAMA Neurol. (2018) 75:236-45. doi: 10.1001/jamaneurol.2017.4266

187. Papma JM, Jiskoot LC, Panman JL, Dopper EG, den Heijer T, Donker Kaat L, et al. Cognition and gray and white matter characteristics of presymptomatic C9orf72 repeat expansion. Neurology. (2017) 89:1256-64. doi: 10.1212/WNL.0000000000004393

188. Kollewe K, Mauss U, Krampfl K, Petri S, Dengler R, Mohammadi B. ALSFRS$\mathrm{R}$ score and its ratio: a useful predictor for ALS-progression. J Neurol Sci. (2008) 275:69-73. doi: 10.1016/j.jns.2008.07.016

189. Rudnicki SA, Berry JD, Ingersoll E, Archibald D, Cudkowicz ME, Kerr DA, et al. Dexpramipexole effects on functional decline and survival in subjects with amyotrophic lateral sclerosis in a Phase II study: subgroup analysis of demographic and clinical characteristics. Amyotroph Lateral Scler Frontotemporal Degener. (2013) 14:44-51. doi: 10.3109/17482968.2012.723723

190. Bede P, Iyer PM, Finegan E, Omer T, Hardiman O. Virtual brain biopsies in amyotrophic lateral sclerosis: diagnostic classification based on in vivo pathological patterns. NeuroImage Clin. (2017) 15:653-8. doi: 10.1016/j.nicl.2017.06.010

191. Bede P, Elamin M, Byrne S, McLaughlin RL, Kenna K, Vajda A, et al. Patterns of cerebral and cerebellar white matter degeneration in ALS. J Neurol Neurosurg Psychiatry. (2015) 86:468-70. doi: 10.1136/jnnp-2014-308172

192. Schuster C, Elamin M, Hardiman O, Bede P. The segmental diffusivity profile of amyotrophic lateral sclerosis associated white matter degeneration. Eur J Neurol. (2016) 23:1361-71. doi: 10.1111/ene.13038

193. Filippini N, Douaud G, Mackay CE, Knight S, Talbot K, Turner MR. Corpus callosum involvement is a consistent feature of amyotrophic lateral sclerosis. Neurology. (2010) 75:1645-52. doi: 10.1212/WNL.0b013e3 $181 \mathrm{fb} 84 \mathrm{~d} 1$

194. Bede P, Bokde A, Elamin M, Byrne S, McLaughlin RL, Jordan N, et al. Grey matter correlates of clinical variables in amyotrophic lateral sclerosis (ALS): a neuroimaging study of ALS motor phenotype heterogeneity and cortical focality. J Neurol Neurosurg Psychiatry. (2013) 84:766-73. doi: 10.1136/jnnp-2012-302674

195. Christidi F, Karavasilis E, Zalonis I, Ferentinos P, Giavri Z, Wilde EA, et al. Memory-related white matter tract integrity in amyotrophic lateral sclerosis: an advanced neuroimaging and neuropsychological study. Neurobiol Aging. (2017) 49:69-78. doi: 10.1016/j.neurobiolaging.2016.09.014

196. Bede P, Elamin M, Byrne S, McLaughlin RL, Kenna K, Vajda A, et al. Basal ganglia involvement in amyotrophic lateral sclerosis. Neurology. (2013) 81:2107-15. doi: 10.1212/01.wnl.0000437313.80913.2c

197. Bede P, Omer T, Finegan E, Chipika RH, Iyer PM, Doherty MA, et al. Connectivity-based characterisation of subcortical grey matter pathology in frontotemporal dementia and ALS: a multimodal neuroimaging study. Brain Imaging Behav. (2018) 12:1696-707. doi: 10.1007/s11682-018-9837-9

198. Agosta F, Ferraro PM, Riva N, Spinelli EG, Domi T, Carrera $\mathrm{P}$, et al. Structural and functional brain signatures of C9orf72 in motor neuron disease. Neurobiol Aging. (2017) 57:206-19. doi: 10.1016/j.neurobiolaging.2017.05.024

199. Bede P, Iyer PM, Schuster C, Elamin M, McLaughlin RL, Kenna K, et al. The selective anatomical vulnerability of ALS: 'disease-defining' and 'diseasedefying' brain regions. Amyotroph Lateral Scler Frontotemporal Degener. (2016) 17:561-70. doi: 10.3109/21678421.2016.1173702

200. Ravits JM, La Spada AR. ALS motor phenotype heterogeneity, focality, and spread: deconstructing motor neuron degeneration. Neurology. (2009) 73:805-11. doi: 10.1212/WNL.0b013e3181b6bbbd 
201. Loewe K, Machts J, Kaufmann J, Petri S, Heinze HJ, Borgelt C, et al. Widespread temporo-occipital lobe dysfunction in amyotrophic lateral sclerosis. Sci Rep. (2017) 7:40252. doi: 10.1038/srep40252

202. Jenkins TM, Alix JJP, David C, Pearson E, Rao DG, Hoggard N, et al. Imaging muscle as a potential biomarker of denervation in motor neuron disease. J Neurol Neurosurg Psychiatry. (2018) 89:248-55. doi: 10.1136/jnnp-2017-316744

203. Jongbloed BA, Haakma W, Goedee HS, Bos JW, Bos C, Hendrikse J, et al. Comparative study of peripheral nerve Mri and ultrasound in multifocal motor neuropathy and amyotrophic lateral sclerosis. Muscle Nerve. (2016) 54:1133-5. doi: 10.1002/mus.25391

204. de Carvalho M, Chio A, Dengler R, Hecht M, Weber M, Swash M. Neurophysiological measures in amyotrophic lateral sclerosis: markers of progression in clinical trials. Amyotroph Lateral Scler. (2005) 6:17-28. doi: 10.1080/14660820410020600

205. Rutkove SB. Clinical measures of disease progression in amyotrophic lateral sclerosis. Neurotherapeutics. (2015) 12:384-93. doi: 10.1007/s13311-014-0331-9

206. Kimura J. Electrodiagnosis in Diseases of Nerve and Muscle: Principles and Practice. Oxford: Oxford University Press (2001).

207. Lewelt A, Krosschell KJ, Scott C, Sakonju A, Kissel JT, Crawford TO, et al. Compound muscle action potential and motor function in children with spinal muscular atrophy. Muscle Nerve. (2010) 42:703-8. doi: $10.1002 /$ mus. 21838

208. Nandedkar SD, Nandedkar DS, Barkhaus PE, Stalberg EV. Motor unit number index (MUNIX). IEEE Trans Biomed Eng. (2004) 51:2209-11. doi: 10.1109/TBME.2004.834281

209. McComas AJ, Fawcett PR, Campbell MJ, Sica RE. Electrophysiological estimation of the number of motor units within a human muscle. J Neurol Neurosurg Psychiatry. (1971) 34:121-31. doi: 10.1136/jnnp.34.2.121

210. Neuwirth C, Braun N, Claeys KG, Bucelli R, Fournier C, Bromberg M, et al. Implementing Motor Unit Number Index (MUNIX) in a large clinical trial: real world experience from 27 centres. Clin Neurophysiol. (2018) 129:175662. doi: 10.1016/j.clinph.2018.04.614

211. Fastenau PS, Denburg NL, Mauer BA. Parallel short forms for the Boston Naming Test: psychometric properties and norms for older adults. J Clin Exp Neuropsychol. (1998) 20:828-34. doi: 10.1076/jcen.20.6.828.1105

212. Zoccolella S, Beghi E, Palagano G, Fraddosio A, Guerra V, Samarelli V, et al. Analysis of survival and prognostic factors in amyotrophic lateral sclerosis: a population based study. J Neurol Neurosurg Psychiatry. (2008) 79:33-7. doi: 10.1136/jnnp.2007.118018

213. Chio A, Logroscino G, Hardiman O, Swingler R, Mitchell D, Beghi E, et al. Prognostic factors in ALS: a critical review. Amyotroph Lateral Scler. (2009) 10:310-23. doi: 10.3109/17482960802566824

214. Elamin M, Phukan J, Bede P, Jordan N, Byrne S, Pender N, et al. Executive dysfunction is a negative prognostic indicator in patients with ALS without dementia. Neurology. (2011) 76:1263-9. doi: 10.1212/WNL.0b013e318214359f

215. Magnus T, Beck M, Giess R, Puls I, Naumann M, Toyka KV. Disease progression in amyotrophic lateral sclerosis: predictors of survival. Muscle Nerve. (2002) 25:709-14. doi: 10.1002/ mus. 10090

216. Westeneng HJ, Debray TPA, Visser AE, van Eijk RPA, Rooney JPK, Calvo A, et al. Prognosis for patients with amyotrophic lateral sclerosis: development and validation of a personalised prediction model. Lancet Neurol. (2018) 7:423-33. doi: 10.1016/S1474-4422(18)30089-9

217. Schuster C, Hardiman O, Bede P. Survival prediction in Amyotrophic lateral sclerosis based on MRI measures and clinical characteristics. BMC Neurol. (2017) 17:73. doi: 10.1186/s12883-017-0854-x

218. Capozzo R, Quaranta VN, Pellegrini F, Fontana A, Copetti M, Carratu P, et al. Sniff nasal inspiratory pressure as a prognostic factor of tracheostomy or death in amyotrophic lateral sclerosis. J Neurol. (2015) 262:593-603. doi: 10.1007/s00415-014-7613-3

219. Polkey MI, Lyall RA, Yang K, Johnson E, Leigh PN, Moxham J. Respiratory muscle strength as a predictive biomarker for survival in amyotrophic lateral sclerosis. Am J Respir Crit Care Med. (2017) 195:86-95. doi: $10.1164 / \mathrm{rccm} .201604-0848 \mathrm{OC}$
220. Gordon PH, Salachas F, Lacomblez L, Le Forestier N, Pradat PF, Bruneteau $\mathrm{G}$, et al. Predicting survival of patients with amyotrophic lateral sclerosis at presentation: a 15-year experience. Neurodegener Dis. (2013) 12:81-90. doi: $10.1159 / 000341316$

221. Kalra S, Vitale A, Cashman NR, Genge A, Arnold DL. Cerebral degeneration predicts survival in amyotrophic lateral sclerosis. I Neurol Neurosurg Psychiatry. (2006) 77:1253-5. doi: 10.1136/jnnp.2006.090696

222. Agosta F, Pagani E, Petrolini M, Sormani MP, Caputo D, Perini M, et al. MRI predictors of long-term evolution in amyotrophic lateral sclerosis. Eur J Neurosci. (2010) 32:1490-6. doi: 10.1111/j.1460-9568.2010. 07445.x

223. Pinto S, Pinto A, de Carvalho M. Phrenic nerve studies predict survival in amyotrophic lateral sclerosis. Clin Neurophysiol. (2012) 123:2454-9. doi: 10.1016/j.clinph.2012.05.012

224. Pijnenburg YA, Verwey NA, van der Flier WM, Scheltens $\mathrm{P}$, Teunissen CE. Discriminative and prognostic potential of cerebrospinal fluid phosphoTau/tau ratio and neurofilaments for frontotemporal dementia subtypes. Alzheimers Dement. (2015) 1:505-12. doi: $10.1016 /$ j.dadm.2015.11.001

225. Oberstadt M, Classen J, Arendt T, Holzer M. TDP-43 and cytoskeletal proteins in ALS. Mol Neurobiol. (2018) 55:3143-51. doi: 10.1007/s12035-017-0543-1

226. Ganesalingam J, An J, Shaw CE, Shaw G, Lacomis D, Bowser R. Combination of neurofilament heavy chain and complement C3 as CSF biomarkers for ALS. J Neurochem. (2011) 117:528-37. doi: $10.1111 / j .1471-4159.2011 .07224 . x$

227. Paganoni S, Macklin EA, Lee A, Murphy A, Chang J, Zipf A, et al. Diagnostic timelines and delays in diagnosing amyotrophic lateral sclerosis (ALS). Amyotroph Lateral Scler Frontotemporal Degener. (2014) 15:453-6. doi: 10.3109/21678421.2014.903974

228. Cudkowicz ME, van den Berg LH, Shefner JM, Mitsumoto H, Mora JS, Ludolph A, et al. Dexpramipexole versus placebo for patients with amyotrophic lateral sclerosis (EMPOWER): a randomised, double-blind, phase 3 trial. Lancet Neurology. (2013) 12:1059-67. doi: 10.1016/S1474-4422(13)70221-7

229. Kernan WN, Viscoli CM, Makuch RW, Brass LM, Horwitz RI. Stratified randomization for clinical trials. J Clin Epidemiol. (1999) 52:19-26. doi: 10.1016/S0895-4356(98)00138-3

230. Nicholson KA, Cudkowicz ME, Berry JD. Clinical trial designs in amyotrophic lateral sclerosis: does one design fit all? Neurotherapeutics. (2015) 12:376-83. doi: 10.1007/s13311-015-0341-2

231. Miller TM, Smith RA, Kordasiewicz H, Kaspar BK. Gene-targeted therapies for the central nervous system. Arch Neurol. (2008) 65:447-51. doi: 10.1001/archneur.65.4.nnr70007

232. Lagier-Tourenne C, Baughn M, Rigo F, Sun S, Liu P, Li HR, et al. Targeted degradation of sense and antisense C9orf72 RNA foci as therapy for ALS and frontotemporal degeneration. Proc Natl Acad Sci USA. (2013) 110:E4530-9. doi: $10.1073 /$ pnas. 1318835110

233. Roche JC, Rojas-Garcia R, Scott KM, Scotton W, Ellis CE, Burman R, et al. A proposed staging system for amyotrophic lateral sclerosis. Brain. (2012) 135(Pt 3):847-52. doi: 10.1093/brain/awr351

234. Chio A, Hammond ER, Mora G, Bonito V, Filippini G. Development and evaluation of a clinical staging system for amyotrophic lateral sclerosis. J Neurol Neurosurg Psychiatry. (2015) 86:38-44. doi: 10.1136/jnnp-2013-306589

235. Thakore NJ, Lapin BR, Kinzy TG, Pioro EP. Deconstructing progression of amyotrophic lateral sclerosis in stages: a Markov modeling approach. Amyotroph Lateral Scler Frontotemporal Degener. (2018) 19:483-494. doi: 10.1080/21678421.2018.1484925

236. Fang T, Al Khleifat A, Stahl DR, Lazo La Torre C, Murphy C, Uk-Mnd Lical S, et al. Comparison of the King's and MiToS staging systems for ALS. Amyotroph Lateral Scler Frontotemporal Degener. (2017) 18:227-32. doi: 10.1080/21678421.2016.1265565

237. Tramacere I, Dalla Bella E, Chio A, Mora G, Filippini G, Lauria G. The MITOS system predicts long-term survival in amyotrophic lateral sclerosis. J Neurol Neurosurg Psychiatry. (2015) 86:1180-5. doi: 10.1136/jnnp-2014-310176 
238. Braak H, Brettschneider J, Ludolph AC, Lee VM, Trojanowski JQ, Del Tredici K. Amyotrophic lateral sclerosis-a model of corticofugal axonal spread. Nat Rev Neurol. (2013) 9:708-14. doi: 10.1038/nrneurol.2013.221

239. Brettschneider J, Del Tredici K, Toledo JB, Robinson JL, Irwin DJ, Grossman $\mathrm{M}$, et al. Stages of pTDP-43 pathology in amyotrophic lateral sclerosis. Ann Neurol. (2013) 74:20-38. doi: 10.1002/ana.23937

240. Kassubek J, Muller HP, Del Tredici K, Brettschneider J, Pinkhardt EH, Lule D, et al. Diffusion tensor imaging analysis of sequential spreading of disease in amyotrophic lateral sclerosis confirms patterns of TDP-43 pathology. Brain. (2014) 137(Pt 6):1733-40. doi: 10.1093/brain/awu090

241. Sherman AV, Gubitz AK, Al-Chalabi A, Bedlack R, Berry J, Conwit R, et al. Infrastructure resources for clinical research in amyotrophic lateral sclerosis. Amyotroph Lateral Scler Frontotemporal Degener. (2013) 14(Suppl. 1):53-61. doi: 10.3109/21678421.2013.779058

242. Sherman A, Bowser R, Grasso D, Power B, Milligan C, Jaffa M, et al. Proposed BioRepository platform solution for the ALS research community. Amyotroph Lateral Scler. (2011) 12:11-6. doi: 10.3109/17482968.2010.539233

243. Otto M, Bowser R, Turner M, Berry J, Brettschneider J, Connor J, et al. Roadmap and standard operating procedures for biobanking and discovery of neurochemical markers in ALS. Amyotroph Lateral Scler. (2012) 13:1-10. doi: 10.3109/17482968.2011.627589

244. Turner MR, Grosskreutz J, Kassubek J, Abrahams S, Agosta F, Benatar M, et al. Towards a neuroimaging biomarker for amyotrophic lateral sclerosis. Lancet Neurol. (2011) 10:400-3. doi: 10.1016/S1474-4422(11)70049-7

245. Johnston MV, Adams HP, Fatemi A. Neurobiology of Disease. Oxford: Oxford University Press (2016).

246. Northeast ALS Consortium. NEALS Member Sites. Available online at: https:// www.neals.org/about-us/neals-member-sites/

247. Beghi E. 127th ENMC International Workshop: implementation of a European registry of ALS. Naarden, The Netherlands, 8-10 October 2004. Neuromuscul Disord. (2006) 16:46-53. doi: 10.1016/j.nmd.2005.10.004
248. Beghi E, Logroscino G, Chio A, Hardiman O, Mitchell D, Swingler $\mathrm{R}$, et al. The epidemiology of ALS and the role of population-based registries. Biochim Biophys Acta. (2006) 1762:1150-7. doi: 10.1016/j.bbadis. 2006.09.008

249. Hobson EV, Baird WO, Partridge R, Cooper CL, Mawson S, Quinn A, et al. The TiM system: developing a novel telehealth service to improve access to specialist care in motor neurone disease using user-centered design. Amyotroph Lateral Scler Frontotemporal Degener. (2018) 19:351-61. doi: 10.1080/21678421.2018.1440408

250. Geronimo A, Wright C, Morris A, Walsh S, Snyder B, Simmons Z. Incorporation of telehealth into a multidisciplinary ALS Clinic: feasibility and acceptability. Amyotroph Lateral Scler Frontotemporal Degener. (2017) 18:555-61. doi: 10.1080/21678421. 2017.1338298

251. Christodoulou G, Gennings C, Hupf J, Factor-Litvak P, Murphy J, Goetz RR, et al. Telephone based cognitive-behavioral screening for frontotemporal changes in patients with amyotrophic lateral sclerosis (ALS). Amyotroph Lateral Scler Frontotemporal Degener. (2016) 17:482-8. doi: $10.3109 / 21678421.2016 .1173703$

Conflict of Interest Statement: The authors declare that the research was conducted in the absence of any commercial or financial relationships that could be construed as a potential conflict of interest.

Copyright (c) 2019 Chipika, Finegan, Li Hi Shing, Hardiman and Bede. This is an open-access article distributed under the terms of the Creative Commons Attribution License (CC BY). The use, distribution or reproduction in other forums is permitted, provided the original author(s) and the copyright owner(s) are credited and that the original publication in this journal is cited, in accordance with accepted academic practice. No use, distribution or reproduction is permitted which does not comply with these terms. 